\title{
Adverse effects in the fish embryo acute toxicity (FET) test: a catalogue of unspecific morphological changes versus more specific effects in zebrafish (Danio rerio) embryos
}

\author{
Rebecca von Hellfeld ${ }^{1}$, Katharina Brotzmann ${ }^{1}$, Lisa Baumann ${ }^{1}$, Ruben Strecker ${ }^{1,2}$ and Thomas Braunbeck ${ }^{* *}$
}

\begin{abstract}
Background: The Fish Embryo Acute Toxicity (FET) test with the zebrafish (Danio rerio) embryo, the OECD test guideline (TG) 236, has been designed as an alternative for acute fish toxicity testing such as the OECD Acute Fish Toxicity Test (TG 203). To provide equivalent sensitivity to the acute fish test, the original FET test was designed to use only four morphological core endpoints: coagulation of the embryo, lack of somite formation, lack of heart beat, and nondetachment of the tail. These endpoints were selected due to (1) their association with mortality, directly or indirectly, (2) improve the practicality for screening by well-trained technical staff, and (3) the endpoints being relatively simple morphological alterations.
\end{abstract}

Results: With the growing need to understand the developmental toxicity of compounds found in the environment, the FET protocol has repeatedly been extended to a multitude of additional morphological endpoints that also allow the monitoring of teratogenicity. As the extensive use of the FET test has generated a multitude of observations in the scientific literature, a harmonisation of the terminology used for the description of the morphological effects seen after chemical exposure has become necessary.

Conclusion: For this end, the present communication provides an overview of both common and selected more specific morphological effects seen in zebrafish embryos after exposure to a wide variety of chemical substances together with suggestions for a harmonised nomenclature.

Keywords: Zebrafish, OECD TG 236, Embryo toxicity, FET test, Teratogenicity, Spinal defects, Lordosis, Kyphosis, Scoliosis, Craniofacial deformation, Yolk malabsorption

\section{Background}

Increasing amounts of anthropogenic compounds entering the environment have led to the need for reliable and accurate acute toxicity tests [1]. Most regulatoryaccepted models for environmental hazard identification and risk assessment of chemicals, pharmaceuticals,

\footnotetext{
*Correspondence: braunbeck@uni-hd.de

${ }^{1}$ Aquatic Ecology and Toxicology, Centre for Organismal Studies, University of Heidelberg, Im Neuenheimer Feld 504, 69120 Heidelberg, Germany

Full list of author information is available at the end of the article
}

biocides, additives, and effluents are based on testing with vertebrate models such as rodents and fish [2]. According to the European Chemicals Agency [3], the Acute Fish Toxicity (AFT) test (OECD Test Guideline 203; [4]) is used for the prospective assessment of individual chemicals for environmental classification according to the Globally Harmonised System of Classification, Labelling and Packaging of Chemicals (GHS), a Predicted NoEffect-Concentration (PNEC), and one potential element of the toxicity criterion for the assessment of Persistence, Bioaccumulation and Toxicity (PBT) assessment [5]. In 
an attempt to improve the assessment of the status of European waters under the Water Framework Directive [6], fish are also utilised for the monitoring of the quality of effluents and surface waters [7]. As a consequence, the AFT test must be conducted in accordance with, for example, OECD Test Guideline 203 [4] or similar guidelines $[8,9]$ and is, by far, the most frequently used vertebrate test for aquatic toxicity assessment.

The frequent use of the AFT test has given rise to both economic and ethical concerns since the early 1980s [10], as the existing data are frequently of poor quality [11], and newer alternative assays are deemed more applicable to long-term hazard identification and risk assessment in an environmental context $[12,13]$. With the implementation of the European chemical policy REACH (Registration, Evaluation, Authorization and Restriction of Chemicals [14]) and the European Cosmetics Directive [15], there is a clear mandate to strongly promote the development of alternative methods according to the 3Rs principle for "Replacement, Reduction, and Refinement" [16] and to preferentially use data generated by alternative methods whenever validated methods are available [14]. All these considerations are calling for the replacement of acute toxicity and teratogenicity testing traditionally founded on animal models by adverse outcome pathway (AOP)based biomarker studies [17, 18] and in vitro models [19] along with more 3R-compatible in vivo models [13, 20]. Most importantly, alternative in vitro assays and in vivo protocols using, e.g., fish embryos are also amenable to high-throughput testing [21-24].

Whereas various European countries as well as Canada and the USA continue requiring conventional AFT testing for whole effluent testing [9], Germany replaced AFT testing in 2003 by a standardised $48 \mathrm{~h}$ test with zebrafish (Danio rerio) embryos [25], and UK also discontinued AFT testing for animal welfare reasons [26]. In an attempt to comply with upcoming EU regulations, the German Environment Agency submitted a draft zebrafish embryo toxicity (FET) test to the OECD Test Guidelines Programme [27]. In July 2013, the FET test was adopted by OECD as Test Guideline 236 [28]. Although ECHA so far refuses to accept the FET test as a stand-alone alternative to OECD TG 203 for regulatory purposes [29], the FET test has found wide acceptance in science and even proved to have a higher sensitivity and better correspondence to humans than other whole organism models [30-32].

Thus, since its implementation, a considerable database on morphological changes in zebrafish embryos following exposure to chemical contaminants has been built [2, 33]. However, there is a striking variability with regard to the endpoints assessed, and many authors list an illdefined set of observations, but neglect other changes, which could be expected. Even worse, there is a significant inconsistency in the nomenclature used, making it difficult to compare the results presented in the literature. Lordosis, for example, is a term frequently used for all types of back curvatures and deformations, whilst these should be divided into lordosis (hyperextension of the back), kyphosis (hunchback) and scoliosis (sideways curvature). Whereas some publications correctly identify lordosis as a hyperextension of the back [34-37], other communications use this term to describe what was actually scoliosis [38]. One paper correctly determined lordosis, but scoliosis was annotated as "spinal column flexure (tail defect)", and alterations noted as kyphosis rather appear as a break in the spinal column than a curvature [39].

To contribute to harmonisation of observations and terminology, the present study provides a catalogue of both more frequently found and less common morphological alterations in zebrafish embryos after exposure to chemicals. To cover a multitude of modes-of-action and different effects, a broad array of 48 chemicals was tested. The resulting catalogue aims to improve the future analyses of observations in FET experiments as well as providing reference for the correct identification of normal versus altered development of the zebrafish embryo.

\section{Methods \\ Chemicals and materials}

All compounds tested were purchased at a minimum purity grade of $98 \%$. Paraquat, mercury (II) chloride, carbaryl, colchicine, rifampicin, clofibrate, sulfisoxazole, and taxol were obtained by Carbosynth (Carbosynth, Compton, UK), rotenone, tebuconazole, and ibuprofen were obtained from TCI (Eschborn, Germany), 4-enevalproic acid was obtained from Santa Cruz Biotechnology (Dallas, USA), acrylamide, carbamazepine, copper (II) sulphate, dibutyl maleate, 3,4-dichloroaniline, 2,2-dimethylvaleric acid, dinitro-o-cresol, 2,4-dinitrophenol, ethanol, 2-ethylbutyric acid, 2-ethylhexanoic acid, hexachlorophene, hexanoic acid, luviquat, malathion, merquat, 2-methylhexanoic acid, 6-methyl-5-heptene2-one, 2-methylpentanoic acid, 1-methyl-4-phenyl-pyridinium iodide $(\mathrm{MPP}+), 1$-octanol, paracetamol, PCB 180, 4-pentenoic acid, prochloraz, 2-propylheptanoic acid, sodium chloride, sodium tetradecyl sulphate (STS), tolbutamide, triclosan, triethylene glycol, 2,3,6-trimethyl phenol, triphenylphosphate, valproic acid, and zinc pyrithione were purchased from Sigma-Aldrich (Deisenhofen, Germany), and dimethyl sulfoxide (DMSO) was ordered from Honeywell International (Offenbach, Germany). Detailed information on test compounds can be found in Additional file 1: Tables S1 and S2. 
All test solutions were freshly prepared prior to use in standardised dilution water (OECD TG 203, [28]); in cases of limited water solubility, the solutions were prepared in $0.1 \%$ DMSO. Carbaryl had to be dissolved in $0.5 \%$ DMSO, and triclosan was prepared in $0.1 \%$ ethanol (Additional file 1: Table S3). $\mathrm{MPP}^{+}$iodide, PCB 180, rifampicin, sulfisoxazole, and taxol were dissolved in $1 \%$ DMSO concentrations. For compounds requiring solvents, a solvent control was also added to the exposure regime at the equivalent concentration required by the compound. The stock solutions of carbamazepine and sodium tetradecyl sulphate were heated up to $90{ }^{\circ} \mathrm{C}$ and $60{ }^{\circ} \mathrm{C}$, respectively, to dissolve. The stock solutions of 2,4-dinitrophenol, dinitro-o-cresol, copper (II) sulphate pentahydrate, paracetamol, paraquat, and sodium tetradecyl sulphate were stored in the dark (Additional file 1: Table S3). The stock solution for colchicine had to be prepared freshly every day, as the compound is highly reactive. Mercury (II) chloride, carbamazepine, copper (II) sulphate, dibutyl maleate, 3,4-dichloroaniline, dinitro$o$-cresol, 2,4-dinitrophenol, ethanol, luviquat, malathion, merquat, 6-methyl-5-heptene-2-one, 1-octanol, prochloraz, sodium chloride, STS, triclosan, triethylene glycol, 2,3,6-trimethyl phenol, and DMSO were tested as part of the OECD TG 236 validation phases, with chemical analytics of water samples having been conducted [40-42].

\section{Fish}

Adult wild-type zebrafish of the 'Westaquarium' strain were obtained from breeding facilities at the Aquatic Ecology and Toxicology Group at the Centre for Organismal Studies (University of Heidelberg; licenced under no. 35-9185.64/BH). Fish maintenance, breeding conditions, and egg production were described in detail elsewhere [1] and are in accordance with internationally accepted standards.

\section{Fish embryo acute toxicity (FET) tests (OECD TG 236)}

The acute toxicity of the test substances was determined according to OECD TG 236 [43]. In brief, freshly laid eggs $[<1 \mathrm{~h}$ post-fertilisation (hpf)] were transferred to $50 \mathrm{ml}$ crystallising dishes filled with the respective test solutions. After control of fertilisation success, eggs were individually transferred to 24-well plates (TPP, Trasadingen, Switzerland) with $2 \mathrm{ml}$ of test solution per well. All test vessels had been pre-incubated (saturated) with the test solutions for at least $24 \mathrm{~h}$. Subsequently, well plates were sealed with self-adhesive foil (SealPlate ${ }^{\mathrm{TM}}$ by EXCEL Scientific, Dunn, Asbach, Germany). Well plates were placed in an incubator at $26.0 \pm 1.0{ }^{\circ} \mathrm{C}$ under a $10 / 14-\mathrm{h}$ dark/light regime. The test medium was renewed each day (semi-static exposure), and all developmental alterations of the embryos were documented at $24,48,72$, and
$96 \mathrm{hpf}$ and in some cases at 120 and $144 \mathrm{hpf}$ (according to OECD TG 236 [43] and Nagel [44], respectively). FET tests with a minimum mortality rate of $30 \%$ in the positive control (4 mg/L 3,4-dichloroaniline) and a maximum effect rate of $10 \%$ in the negative control (dilution water) at $96 \mathrm{hpf}$ were classified as valid.

In addition to the endpoints specified by OECD TG 236, (1) coagulation of fertilised eggs, (2) lack of somite formation, (3) non-detachment of tail bud, and (4) lack of heart beat (OECD, 2013), any other observation was recorded as further lethal or sublethal endpoints. Common examples were reduced heart beat or reduced blood flow, inhibited or missing pigmentation, delayed or altered development, modified movement(s), distortion of the spine, and formation of various types of oedemata. In case of evidence for delayed toxicity, the standard exposure duration of $96 \mathrm{~h}$ given in OECD TG 236 (OECD, 2013) was extended to 120 or even $144 \mathrm{hpf}$ for more obvious expression of observations. However, the developmental stage at the end of the experiments never exceeded the limits for unprotected developmental stages set by the current EU animal welfare legislation $[45,46]$. FET tests were run in four replicates, for compounds with previously conducted small range-finding studies, two full FET tests were accepted, if these did not vary from the previous findings. The embryos were analysed under an Olympus CKX41 inverted microscope (Olympus, Hamburg, Germany), and images were captured using an Olympus C5040 AUD camera.

\section{Data analysis}

To better highlight the area(s) of interest, micrographs were optimised (e.g., adjustment of light intensity) using Photoshop CS5 (Adobe, Munich, Germany). Lethal concentrations (LC) and effect concentrations (EC) were calculated at effect levels of 10 and $50 \%$ based on probit analysis using linear maximum-likelihood regression with ToxRat $^{\mathrm{TM}}$ (ver. 2.10.03; ToxRat ${ }^{\mathrm{TM}}$ Solutions, Alsdorf, Germany), with both lethal and sublethal effects included into the calculation of EC and LC values [13].

\section{Results and discussion}

Formal toxicity data derived from fish embryo acute toxicity (FET) tests

The toxicity of the test compounds was determined after $96 \mathrm{~h}$ of exposure as both EC and LC at the 10 and 50\% levels (Table 1). The five test compounds dissolved in $1 \%$ DMSO $\left(\mathrm{MPP}^{+}\right.$iodide, PCB 180, rifampicin, sulfisoxazole, and taxol) due to poor solubility did not show any effects. Overall, it became evident that where 96 and 120/144 hpf values were provided, the toxicity of the compounds showed only minor variation. Whereas DMSO, for example, was markedly less toxic at 144 than at $96 \mathrm{hpf}$, other 
Table 1 Acute and sublethal toxicity data from the fish embryo tests with zebrafish (Danio rerio) as computed by ToxRat ${ }^{\text {TM }}$

\begin{tabular}{|c|c|c|c|c|c|c|c|c|c|}
\hline & \multirow[t]{2}{*}{$\mathbf{n}$} & \multicolumn{4}{|c|}{ Toxicity $96 \mathrm{~h}$ (mg/L) } & \multicolumn{4}{|c|}{ Toxicity $120 \mathrm{~h}(\mathrm{mg} / \mathrm{L}) / 144 \mathrm{~h}(\mathrm{mg} / \mathrm{L})^{a}$} \\
\hline & & $\mathrm{EC}_{10}$ & $\mathrm{EC}_{50}$ & $\mathrm{LC}_{10}$ & $\mathrm{LC}_{50}$ & $\mathrm{EC}_{10}$ & $\mathrm{EC}_{50}$ & $\mathrm{LC}_{10}$ & $\mathrm{LC}_{50}$ \\
\hline Acrylamide & 4 & 75.400 & 94.000 & 166.600 & 199.300 & & & & \\
\hline Carbamazepine & 3 & 42.700 & 81.330 & 138.760 & 164.920 & 53.400 & 62.600 & 124.500 & 147.400 \\
\hline Carbaryl & 2 & 2.200 & 2.400 & 6.600 & 12.200 & & & & \\
\hline Clofibrate & 2 & 200.000 & 300.000 & 600.000 & 1100.000 & & & & \\
\hline Colchicine & 4 & 23.100 & 32.400 & 32.500 & 41.400 & & & & \\
\hline Copper (II) sulphate & 3 & 0.400 & 0.700 & 0.600 & 0.800 & 0.200 & 0.600 & 0.600 & 0.800 \\
\hline Dibutyl maleate & 3 & 0.400 & 0.600 & 0.500 & 0.700 & & & & \\
\hline 3,4-Dichloroaniline & 3 & 1.200 & 1.900 & 1.600 & 2.400 & & & & \\
\hline Dimethyl sulfoxide & 3 & $14,460.000$ & $20,100.000$ & $27,200.000$ & $36,560.000$ & $20,250.000$ & $24,610.000$ & $25,390.000$ & $33,880.000$ \\
\hline 2,2-Dimethylvaleric acid & 2 & 56.600 & 64.300 & 71.700 & 77.200 & 54.400 & 62.500 & 71.700 & 77.200 \\
\hline Dinitro-o-cresol & 3 & 0.300 & 0.400 & 0.400 & 0.500 & 0.300 & 0.400 & 0.400 & 0.500 \\
\hline 2,4-Dinitrophenol & 3 & 2.000 & 2.700 & 3.400 & 4.100 & 1.600 & 2.400 & 2.000 & 2.700 \\
\hline Ethanol & 3 & 5800.00 & 7840.000 & 8650.000 & $11,3000.000$ & & & & \\
\hline 2-Ethylbutyric acid & 3 & 20.100 & 47.100 & 68.500 & 95.700 & 32.300 & 58.300 & 61.200 & 83.700 \\
\hline 2-Ethylhexanoic acid & 3 & 5.600 & 20.800 & 24.200 & 40.000 & 7.200 & 16.400 & 24.200 & 38.200 \\
\hline Hexachlorophene & 2 & 0.004 & 0.005 & 0.007 & 0.008 & & & & \\
\hline Hexanoic acid & 2 & 62.500 & 69.400 & 75.300 & 76.100 & 61.900 & 67.000 & 74.600 & 77.200 \\
\hline Ibuprofen & 2 & 4.700 & 10.800 & 31.700 & 37.300 & & & & \\
\hline Luviquat & 3 & 0.300 & 0.500 & 0.400 & 0.900 & 0.400 & 0.600 & 0.300 & 0.800 \\
\hline Malathion & 3 & 0.800 & 1.200 & 2.800 & 3.500 & 0.800 & 1.100 & 2.000 & 2.600 \\
\hline Merquat & 3 & 0.200 & 0.300 & 0.300 & 0.500 & 0.200 & 0.300 & 0.200 & 0.500 \\
\hline 2-Methylhexanoic acid & 2 & 46.500 & 53.900 & 75.200 & 84.100 & 28.700 & 42.600 & 75.300 & 84.100 \\
\hline 6-Methyl-5-heptene-2-one & 3 & 54.500 & 81.700 & 76.100 & 139.700 & & & & \\
\hline Methylmercury (II) chloride & 3 & 0.020 & 0.030 & 0.030 & 0.040 & 0.0100 & 0.020 & 0.030 & 0.030 \\
\hline 2-Methylpentanoic acid & 3 & 35.900 & 53.500 & 59.800 & 77.000 & 43.200 & 54.400 & 52.300 & 67.800 \\
\hline $\begin{array}{l}\text { 1-Methyl-4-phenyl-pyridinium } \\
\text { iodide }\end{array}$ & 3 & \multicolumn{8}{|c|}{ No effects observable up to solubility limits (up to $1 \%$ final DMSO concentration) ${ }^{b}$} \\
\hline 1-Octanol & 3 & 8.700 & 12.400 & 13.700 & 18.900 & 10.100 & 15.100 & 13.200 & 18.400 \\
\hline Paracetamol & 2 & 200.000 & 300.000 & 1000.000 & 1200.000 & & & & \\
\hline Paraquat & 2 & 328.700 & 353.200 & 933.800 & 1161.400 & 384.700 & 545.900 & 721.100 & 855.000 \\
\hline 4-Pentenoic acid & 2 & 52.100 & 60.200 & 90.800 & 107.100 & 52.200 & 60.100 & 63.500 & 103.500 \\
\hline PCB 180 & 3 & \multicolumn{8}{|c|}{ No effects observable up to solubility limits (up to $1 \%$ final DMSO concentration) ${ }^{b}$} \\
\hline Prochloraz & 3 & 1.700 & 3.800 & 2.300 & 4.500 & 1.500 & 3.200 & 2.200 & 4.300 \\
\hline 2-Propylheptanoic acid & 3 & 3.400 & 4.100 & 10.000 & 13.500 & 2.400 & 3.100 & 8.900 & 11.500 \\
\hline Rifampicin & 3 & \multicolumn{8}{|c|}{ No effects observable up to solubility limits (up to $1 \%$ final DMSO concentration) ${ }^{b}$} \\
\hline Rotenone & 2 & 0.004 & 0.007 & 0.006 & 0.010 & & & & \\
\hline Sodium chloride & 3 & 1090.00 & 3370.000 & 2860.000 & 5910.000 & & & & \\
\hline Sodium tetradecyl sulphate & 3 & 0.300 & 0.300 & 0.300 & 0.300 & 0.200 & 0.300 & 0.300 & 0.300 \\
\hline Sulfisoxazole & 3 & \multicolumn{8}{|c|}{ No effects observable up to solubility limits (up to $1 \%$ final DMSO concentration) ${ }^{b}$} \\
\hline Taxol & 3 & \multicolumn{8}{|c|}{ No effects observable up to solubility limits (up to $1 \%$ final DMSO concentration) ${ }^{b}$} \\
\hline Tebuconazole & 2 & 2.300 & 5.300 & 15.000 & 17.300 & & & & \\
\hline Tolbutamide & 2 & 54.300 & 116.900 & 223.200 & 278.600 & & & & \\
\hline Triclosan & 3 & 0.100 & 0.200 & 0.200 & 0.300 & & & & \\
\hline Triethylene glycol & 3 & $31,220.000$ & $35,700.000$ & $45,220.000$ & $54,220.000$ & $26,400.000$ & $32,300.000$ & $45,000.000$ & $52,200.000$ \\
\hline 2,3,6-Trimethyl phenol & 3 & 9.800 & 12.300 & 10.500 & 14.100 & & & & \\
\hline Triphenylphosphate & 2 & 0.300 & 0.500 & 1.400 & 1.600 & & & & \\
\hline 4-ene-Valproic acid & 2 & 24.700 & 37.400 & 41.900 & 56.100 & 28.400 & 33.100 & 49.800 & 68.900 \\
\hline Valproic acid & 3 & 3.100 & 9.100 & 26.200 & 56.900 & 6.200 & 11.800 & 33.300 & 62.700 \\
\hline Zinc pyrithione & 3 & 0.002 & 0.005 & LC $>$ solubili & & & & & \\
\hline
\end{tabular}

Date are given as mean \pm SD from $\mathrm{n}$ independent replicates

a Data for $144 \mathrm{~h}$ in italics

b For data on solubility limits, see Additional file 1: Table S2 
compounds showed more diverse changes: 2-methylhexanoic acid, e.g., did not show any change in acute toxicity between 96 and $120 \mathrm{hpf}$, and sublethal toxicity was lower at 120 than at $96 \mathrm{hpf}$. Paraquat, on the other hand, showed less symptoms of sublethal toxicity at 120 than at $96 \mathrm{hpf}$, whereas its acute toxicity was higher at 96 than at 120 hpf. Although the FET test has very frequently been conducted over the past years, effect and lethal concentrations (EC and LC, respectively) resulting from these tests are only rarely found in the open literature, but have frequently been incorporated into online databases such as EnviroTox (http://www.EnviroToxdatabase.org) or ECOTOX (https://cfpub.epa.gov/ecotox). In many cases, however, only exposure concentrations, single values, or concentrations of interest are given or represented graphically. Illustrating the point, out of 48 substances of diverse chemical classes and applications examined in the present study, the $\mathrm{LC}_{50}$ value for only 6 of them had previously been published, and only for one compound, the $\mathrm{EC}_{50}$ value was available. This points towards a large gap in the current scientific standing, as these values often build the foundation for many higher tier assays, such as behavioural tests and more specific and mechanistic toxicity assessment with adult animals.

\section{Lethal and sublethal effects in the Fish Embryo Acute Toxicity (FET) tests}

Table 2 provides a summary of all observations recorded during the analysis of morphological endpoints. It should be noted that the gastrulation arrest observed with hexachlorophene was added as a sub-type of the first core endpoint ("coagulation") listed by OECD TG 236 (OECD, 2013). For reasons of a more detailed description, the fourth core endpoint ("lack of heart beat") of OECD TG 236 was subdivided into partial or complete lack of both heart beat and blood flow as well as blood congestion (formation of blood islands within extended blood vessels).

Compounds such as 2,2-dimethylvaleric acid, hexanoic acid, 2-propylheptanoic acid, and 4-ene-valproic acid caused a large number of the developmental alterations (termed as "endpoints") observed (18, 18, 17 , and 19 endpoints, respectively). Another compound found to induce a large number of endpoints was valproic acid, inducing yolk deformation, reduced yolk resorption, reduction of pigmentation, lordosis, craniofacial deformations, and 11 other endpoints. In contrast, there were compounds causing only a limited set of alterations, part of which also varied significantly in severity. For example, compounds such as 2,4-dinitrophenol (6), luviquat (6), malathion (7), merquat (7), sodium chloride (7), and triclosan (6) caused overall fewer endpoints. Finally, for MPP+, PCB 180, rifampicin, sulfisoxazole, and taxol, neither acute nor sublethal toxicity could be recorded at concentrations up to the solubility limits (Table 1).

Likewise, with respect to specific endpoints, some endpoints were seen after exposure to the majority of tested compounds. As is evident from Table 2, formation of oedemata could be observed with any of the 45 substances tested positive. Therefore, oedemata in zebrafish appear to be of very little mechanistic value and have to be categorised as an unspecific side effect of both acute and sublethal toxicity [47, 48], although oedemata were listed as changes typical of cardiotoxicity [49]. Oedemata have also been described after exposure to petroleum oils [50], nanomaterials [51], parabens [52], endocrine disruptors [53], flame retardants [54, 55], pesticides [56], and numerous other classes of compounds. Likewise, physicochemical parameters such as temperature are capable of inducing oedemata in zebrafish embryos [57].

Other endpoints, such as otolith deformation and eye malformations, were caused by only 4 and 6 of the 50 compounds tested, respectively. According to the literature, otolith deformation has only been reported after exposure to bisphenol A [58], carbamazepine, diclofenac, and metoprolol [59], as well as ethanol and acetaldehyde [60], whereas various kinds of eye malformation are commonly observed in zebrafish embryos.

When conducting FET tests, complete lists of deviations from the normal embryonic development must be compiled to fully exploit the power of this test and to add to a deeper insight into the mechanisms of action of the compound(s) in question. Only a complete list of observations can finally be utilised to determine the next steps to take in the compound's risk assessment and for planning of further tests with adults. The present work has provided the proof of concept that certain endpoints occur with a higher frequency than others, leading to the question towards the underlying mechanisms of action and biological pathways. Further research should aim to determine these, providing a greater insight into the underlying toxicology of the compounds causing these more specific endpoints.

\section{Normal development of zebrafish embryos}

Figures 1, 2, 3, 4, and 5 illustrate the normal development of zebrafish embryos over $120 \mathrm{~h}$. Briefly, after $24 \mathrm{~h}$ (Fig. 1), the principle organisation of the embryo is already discernible, and anatomical structures such as somites, notochord, otoliths, and eye anlage as well as the heart anlage can be localised. Overall body length can be measured, and the embryo shows first erratic movements (tail curling). 


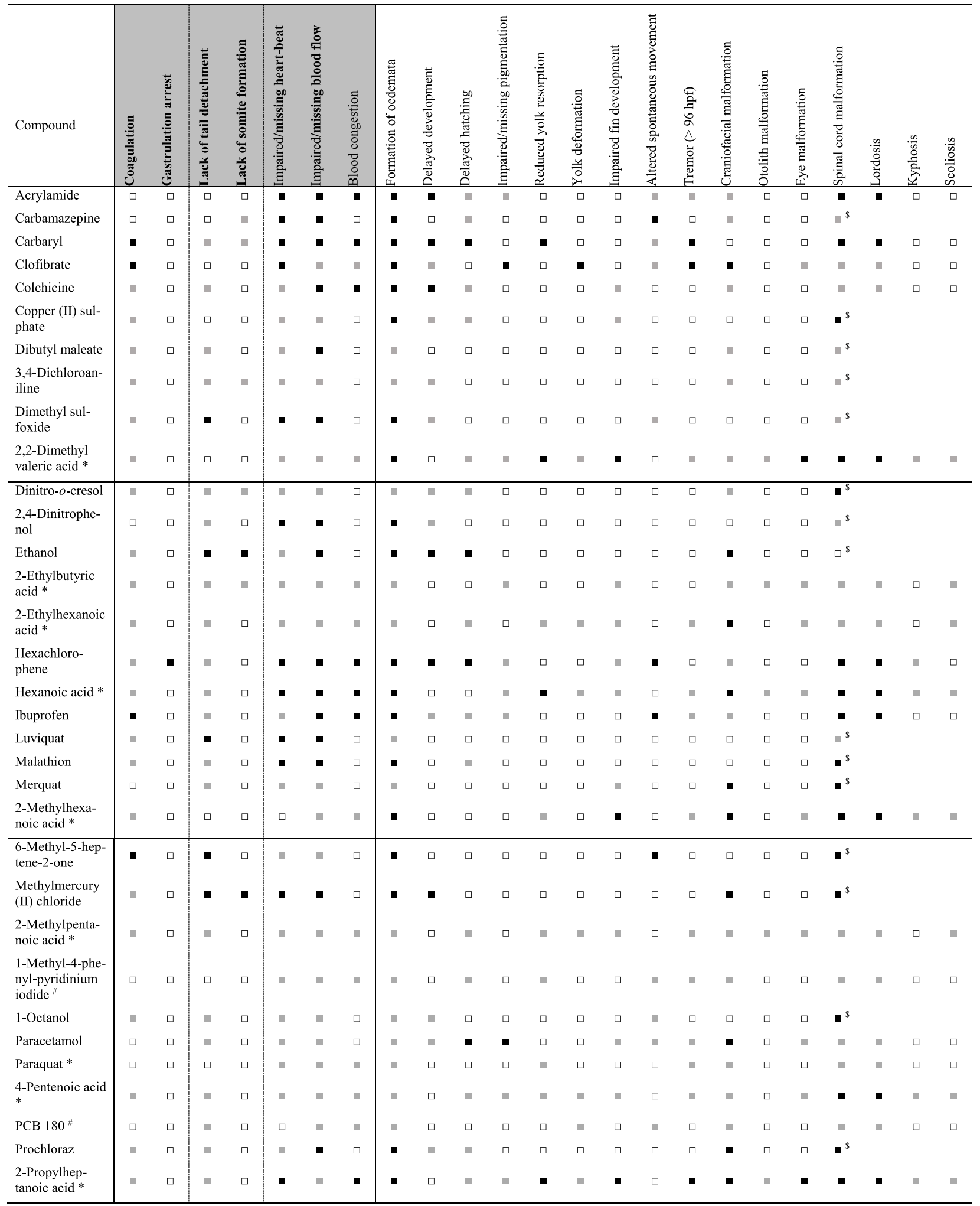


Table 2 (continued)

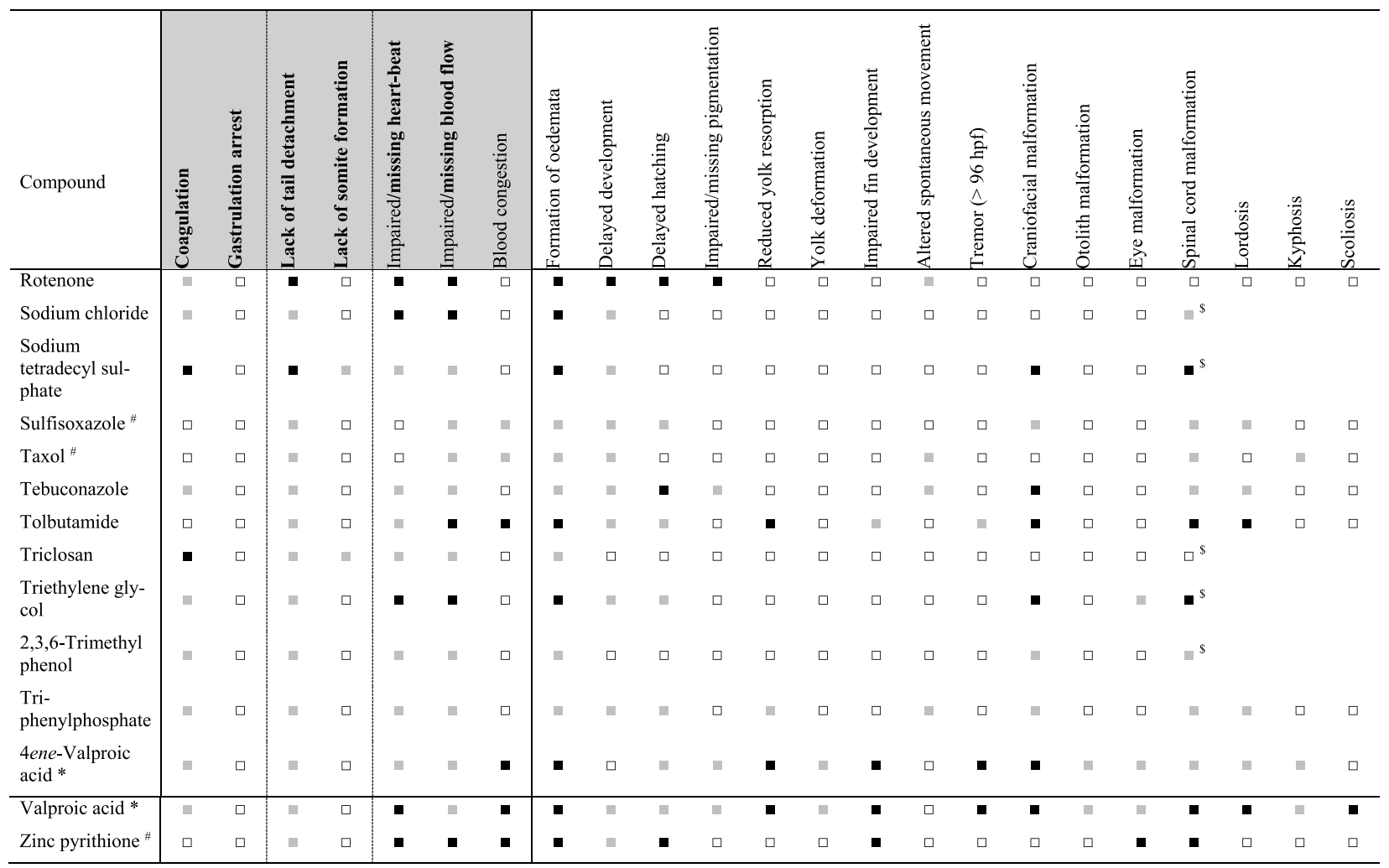

The four core endpoints listed by OECD TG $236(\mathrm{OECD}, 2013)$ are indicated in bold. Frequency of occurrence: - - frequent and/or at concentrations $<\mathrm{LC} \mathrm{C}_{10} \lll-\leq 20 \%$ of exposed organisms and/or only at concentrations $>\mathrm{LC}_{10} ; \square-$ not observed for this compound

* Additional determination at 120 and/or $144 \mathrm{hpf}$ (cf. Table 1); ${ }^{\sharp}$ no symptoms of acute lethality at highest solubility in a final DMSO concentration of $1 \% ;{ }^{5}$ no differentiation for specific spinal cord deformations; endpoints grouped under general "spinal cord malformation"

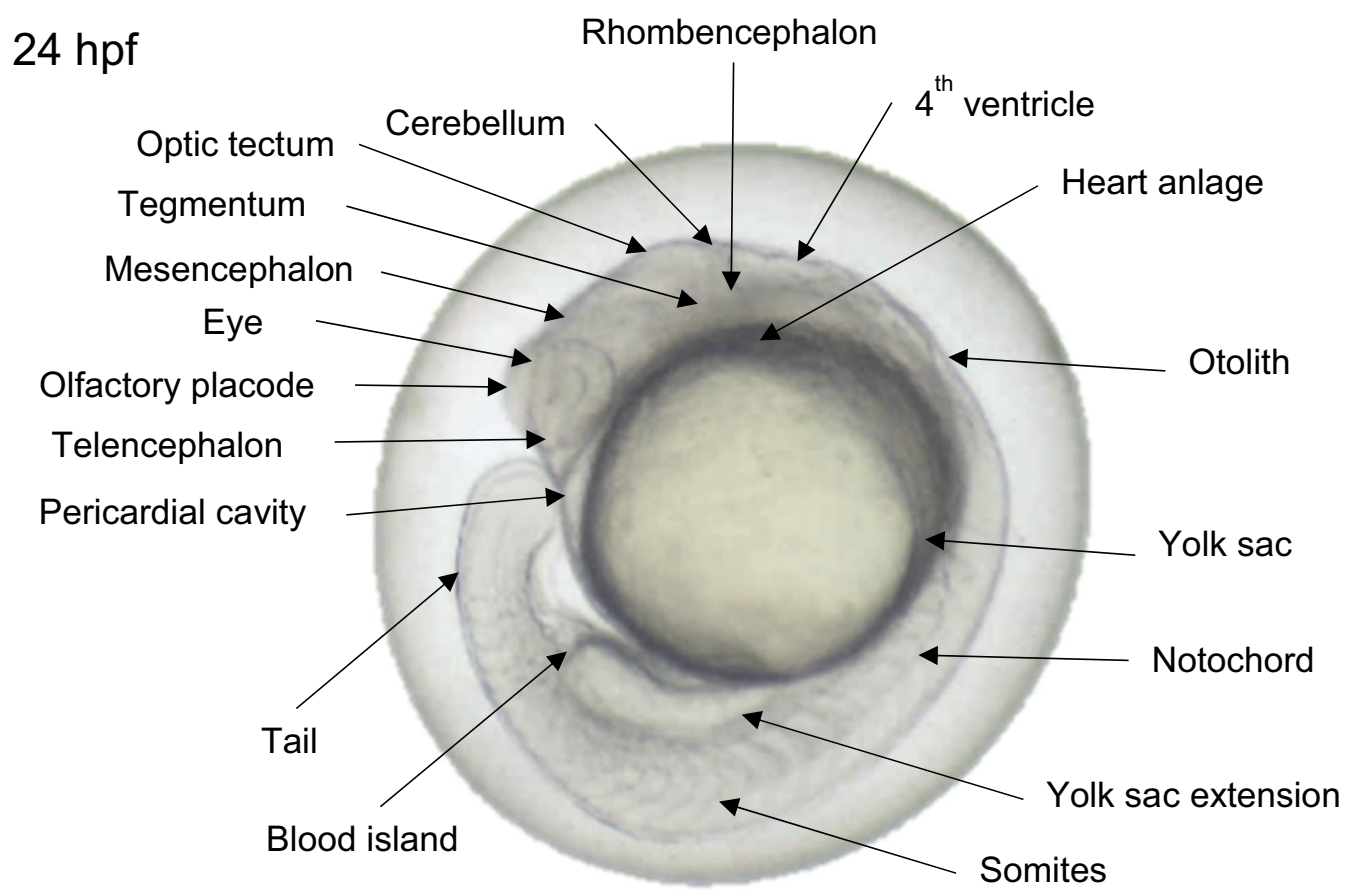

Fig. 1 Morphology of normal zebrafish (Danio rerio) embryo at $24 \mathrm{hpf}$ 

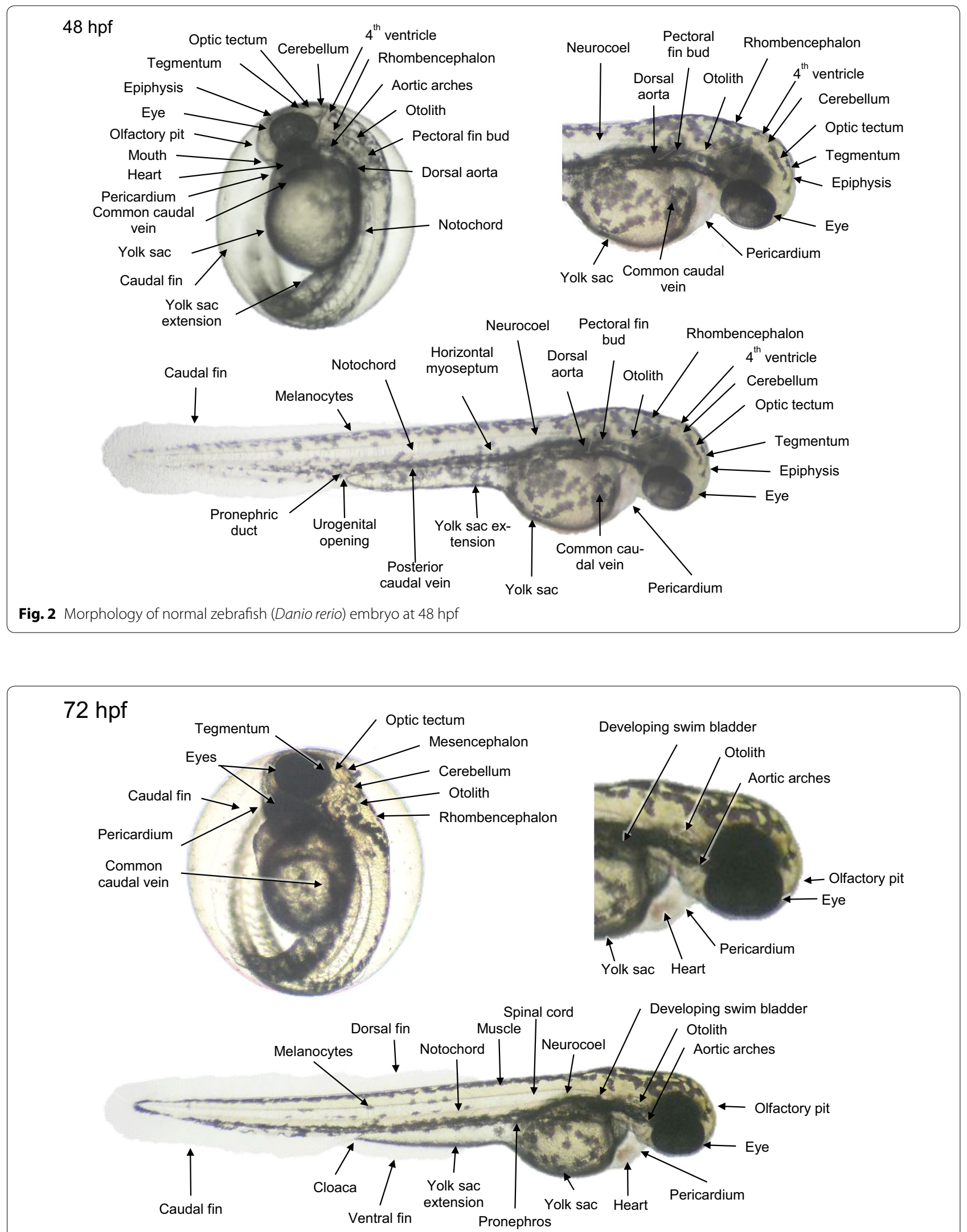

Fig. 3 Morphology of normal zebrafish (Danio rerio) embryo at $72 \mathrm{hpf}$ 


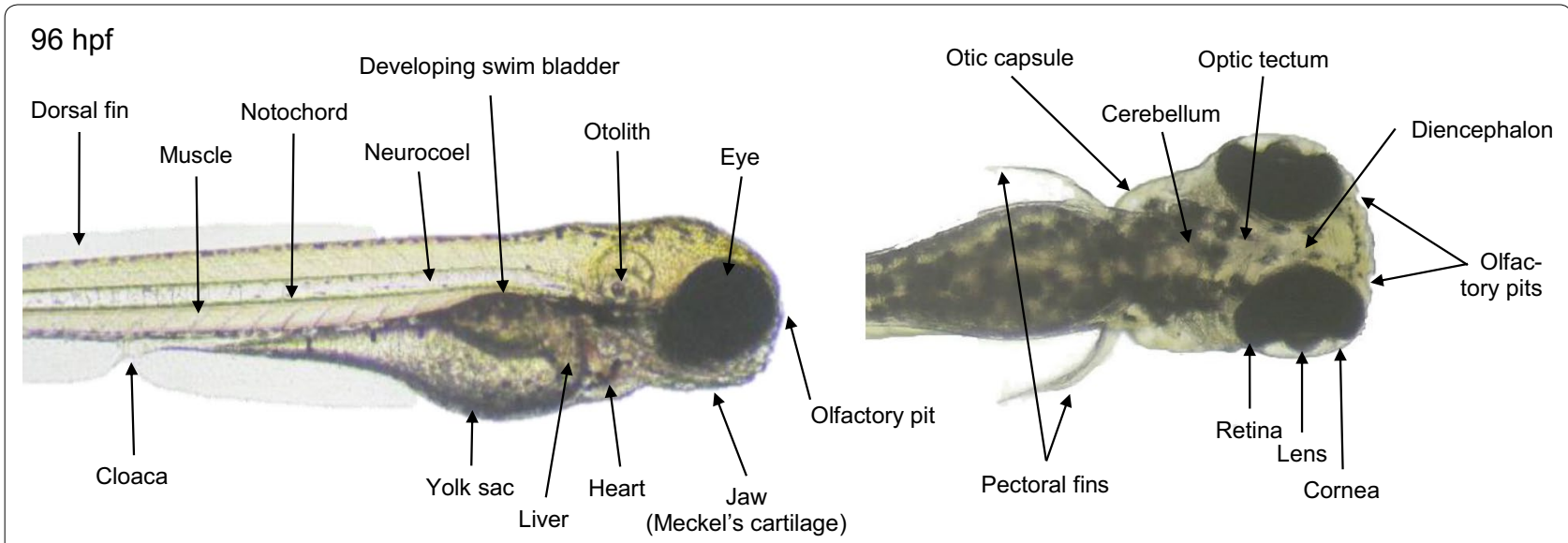

Fig. 4 Morphology of normal zebrafish (Danio rerio) embryo at 96 hpf

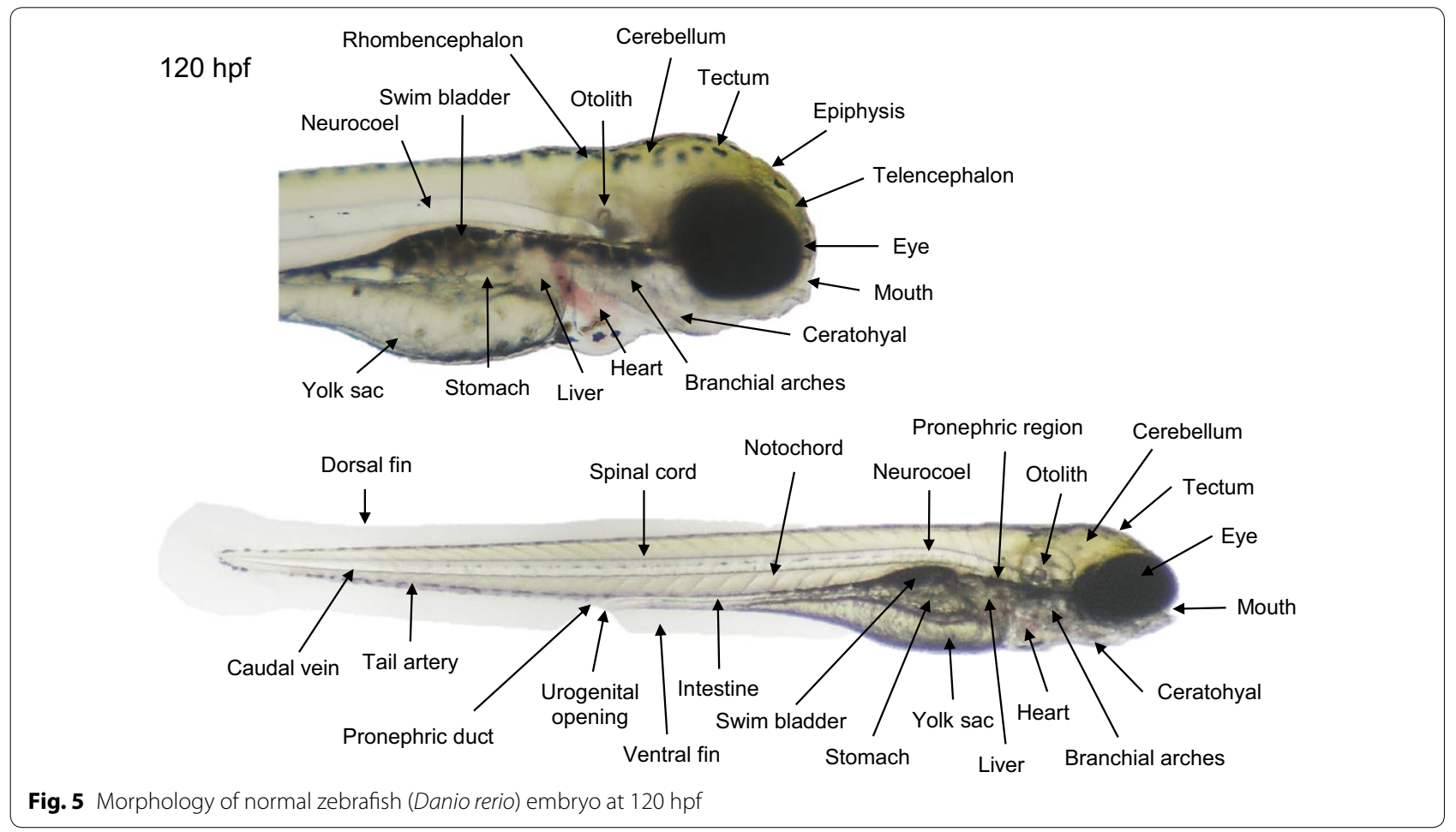

Figure 2 provides an overview of the structures formed by $48 \mathrm{hpf}$; at this age, dechorionation can easily be performed [61] for better access to embryonic structures. At an age of $48 \mathrm{~h}$, craniofacial features have further developed and can be utilised for assessing the disruption of cartilaginous structures [62]. Blood flow and an un-looped heart region can be discerned for the assessment of cardiac and circulatory malformations. Likewise, major sensory organs such as eye and ear are fully developed, and various components of the brain and the spine above the notochord can be distinguished (Fig. 2). At $48 \mathrm{hpf}$, embryos show an increasing number of epidermal pigment cells. Furthermore, the caudal fin as well as the buds of the pectoral fins have formed.

After $72 \mathrm{hpf}$, the overall anatomy is mainly developed and the embryos are ready for hatch (Fig. 3). The $\mathrm{S}$-shaped heart loop allows for effective circulation, and the curvature of the back enables the correct determination of modifications such as lordosis, scoliosis, and kyphosis. The fins have developed further, and after 
hatching, the first behavioural alterations based on active swimming can be recorded.

In 96-h-old zebrafish embryos (Fig. 4), resorption has significantly reduced the volume of the yolk sac, the swim bladder has formed, and the intestinal tract is fully developed. After 96 h, all embryos should have hatched. After $120 \mathrm{~h}$, embryos have almost completely resorbed the yolk, and facial features have flattened further to allow for active capturing of prey (Fig. 5), which effectively starts between 128 and $144 \mathrm{hpf}$ [63].

\section{Core endpoints of acute lethality in the development of zebrafish embryos}

Developmental alterations observed during the FET tests of the compounds listed above are summarised in Figs. 6, 7, 8, and 9. Figure 6 illustrates coagulation, gastrulation arrest, and the lack of tail detachment and somite formation as 3 out of 4 core endpoints of the OECD TG 236 for acute lethality. Coagulation frequently already occurs at $24 \mathrm{hpf}$ (Fig. 6a) and is indicative of early death; only rarely, coagulation can be seen in later developmental stages: Zebrafish embryos exposed to colchicine clearly displayed active heart beat, but blood flow was severely reduced, the general development was delayed, and the body typically started coagulating from the tail and the yolk sac (Fig. 6b). With the majority of articles pertaining to FET results focusing on EC and LC values, coagulation is one of the more commonly mentioned endpoints. Gastrulation arrest (Fig. 6c) has often been considered as a precursor of coagulation, but may also be observed in embryos with severely delayed development, which is usually recorded as a sublethal endpoint. Lack of tail detachment also occurs in early development (Figs. 6d-f, with increasing severity) and can either be an indicator of general delayed

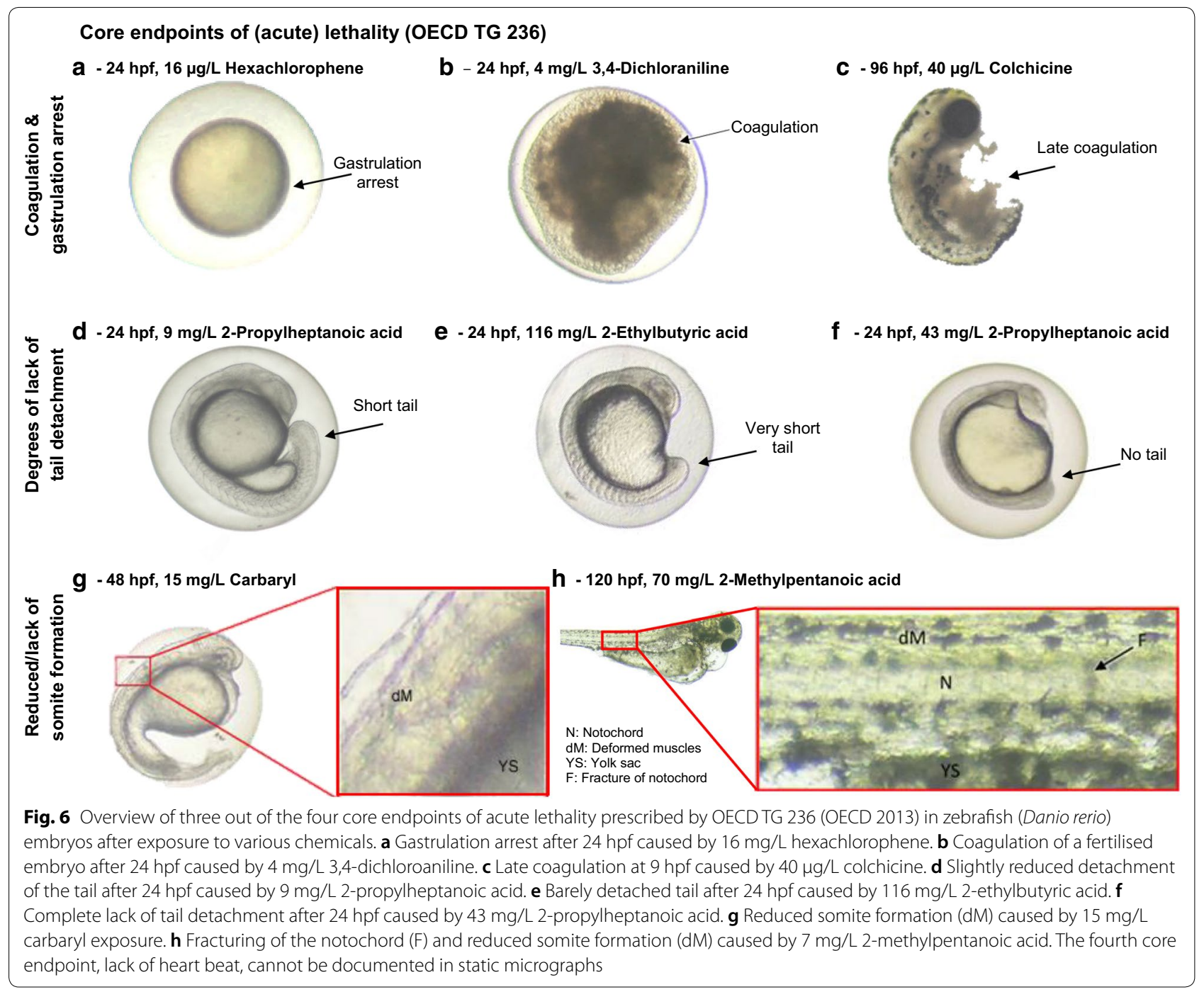




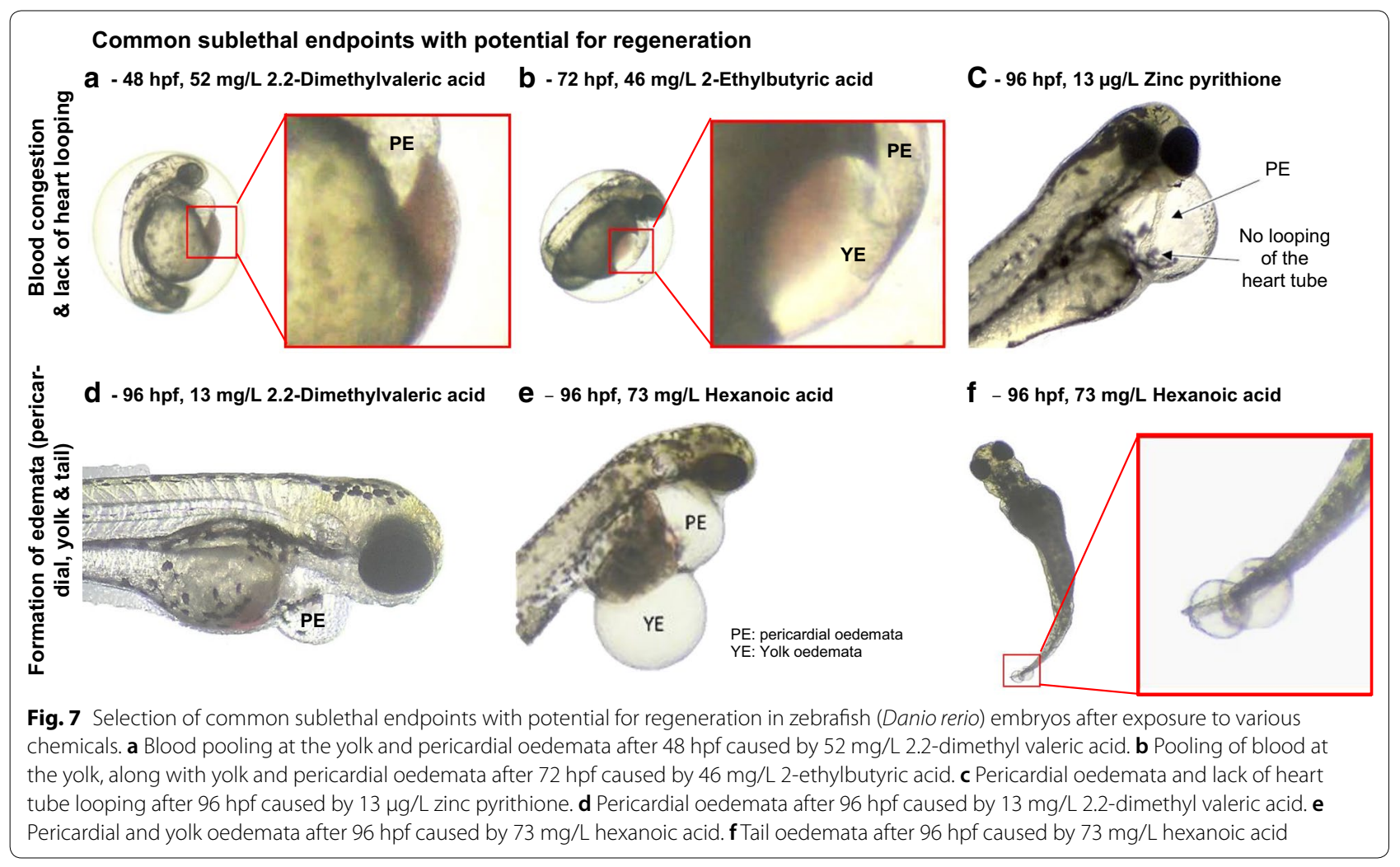

development or, in severe cases, develop into lethality. The underlying mechanisms for non-detachment of the tail are not yet understood, and more attention should be paid not only to its occurrence and severity, but also to its potential for recovery.

The core endpoints of acute toxicity as specified by OECD TG 236 further include lack of somite formation, an endpoint which becomes evident from $24 \mathrm{hpf}$. The insert in Fig. 6g illustrates the gradual disappearance of pylon-shaped somites (dM) above the yolk sac (YS) into a diffuse mass of tissues. Manipulation of the plane of focus also allows the detection of fractures of the spinal cord (Fig. 6h insert). Somites have been found to be involved in the development of the vertebrae, ribs, skeletal muscles, and skin, for example [64], indicating that correct formation of somites is vital for the later development of the embryo. Although the OECD protocol for the FET explicitly specifies somite formation as a key endpoint, reference to alterations of somite formation is scarce in the literature [65-68], which may be due to technical difficulties in revealing this endpoint and only Brannen et al. [69] recorded the number of somites.

\section{Sublethal morphological alterations in zebrafish embryos with potential for regeneration}

Figure 7 presents commonly observed sublethal endpoints with high recovery potential. To allow for a more detailed assessment, the OECD TG 236 core endpoint lack of heart beat was subdivided into partial and complete lack of heart beat, blood flow, as well as blood congestion. Lack of blood circulation can, by definition, not be captured in an image. In contrast, blood congestion characterised by the accumulation of blood cells, especially within pericardial (Fig. 7a) and yolk oedemata (Fig. 7b), can frequently be observed in conjunction with a severe reduction of both blood flow and heart-beat rate. Some authors (e.g., Brannen et al. [69]) did not differentiate cardiovascular effects, but summarised such effects under "cardiovascular function" and "heart rate", thus hampering a direct comparison of results.

The literature on the development of the zebrafish cardiovascular system has described heart looping (Fig. 7c) in great detail [70-72], linking developmental alterations to oxidative stress [73], lipid metabolism [70], neural crest cell migration [71, 72], early cardiomyocyte differentiation [74], Ah receptor-mediated biotransformation [75], or retinoic acid metabolism and hox signalling [76-78]. However, 


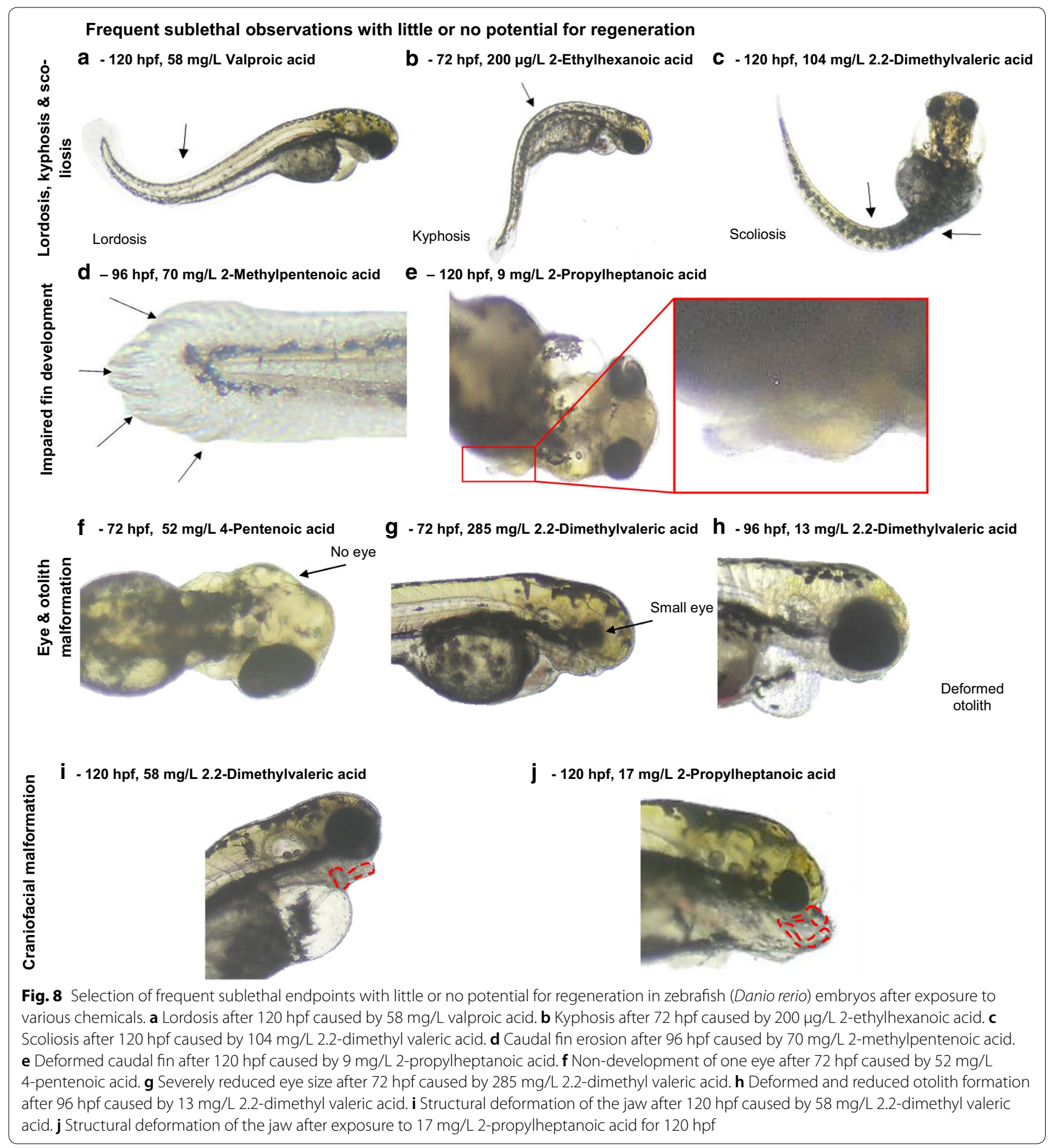

such observations have only rarely been mentioned in the (eco)toxicological literature [79]. In mild cases, pericardial oedemata (Fig. 7d) resemble enlarged pericardium, whereas severe cases can be identified as distended thinwalled cavities surrounding the heart (Fig. 7e: PE). Yolk oedemata (Fig. 7e: YE) may develop into cavities within the yolk itself or concentrate in the periphery underneath the yolk sac. Oedemata are not restricted to pericardial and yolk regions, but may appear along the entire body (Fig. 7f), found among the most frequent observations in the present study (Table 2) and have, therefore, to be classified as unspecific. Likewise, oedemata have commonly been mentioned in the literature (for recent examples, see [80-82], and some authors differentiated between yolk, 


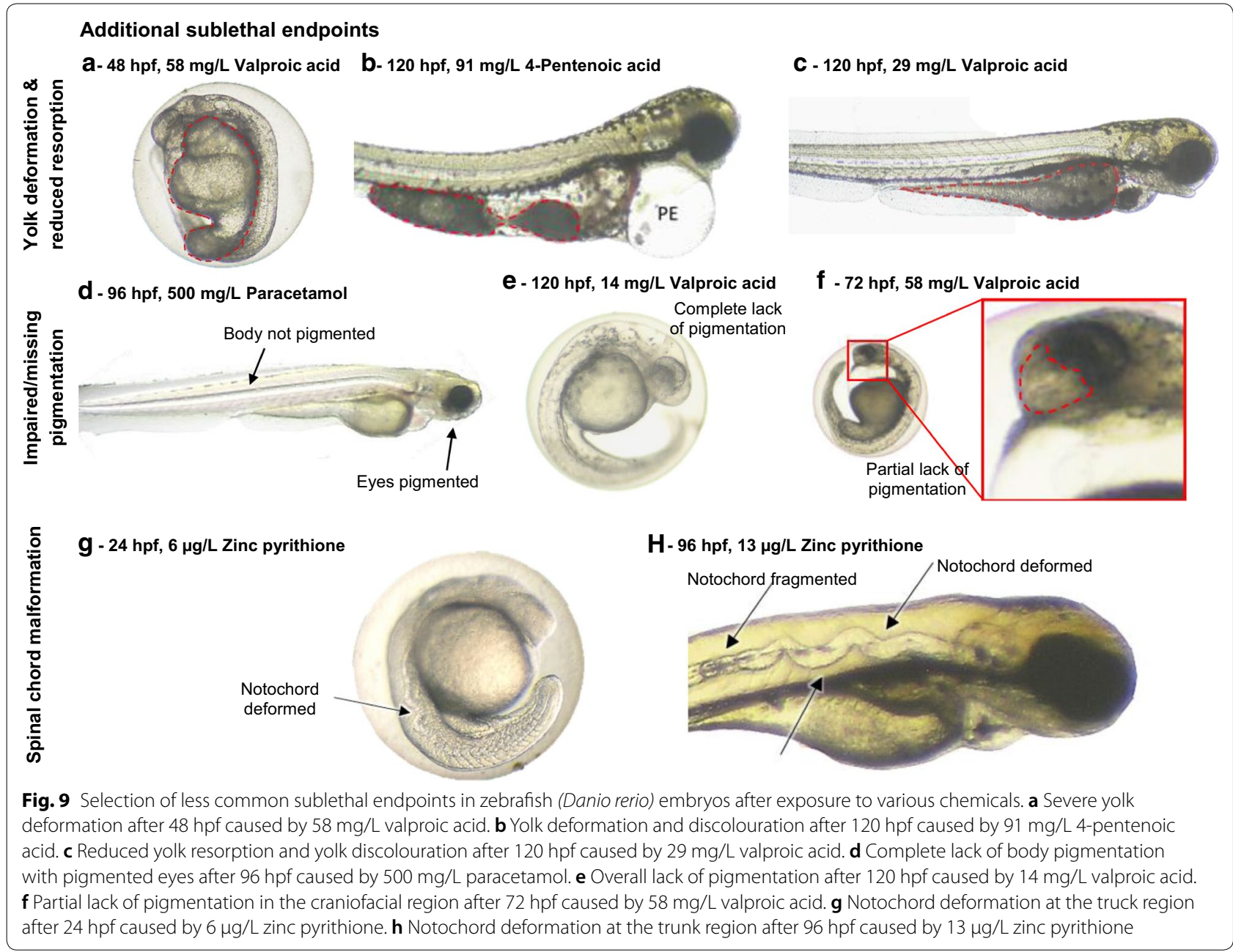

pericardial, and facial oedemata [83], whereas others only listed "heart morphology" as a summary endpoint [69]. If not too severe, any kind of oedemata seen in zebrafish embryo development seems to be reversible.

\section{Sublethal morphological alterations in zebrafish embryos with little potential for regeneration}

Frequently occurring sublethal endpoints which rarely recover are given in Fig. 8. For instance, three types of spinal curvature can be differentiated: (1) lordosis, an inward curving of the spine (Fig. 8a), (2) kyphosis, an outward curving (Fig. 8b), and (3) scoliosis, a sideways curving (Fig. 8c). As discussed above, these are three distinctly different pathologies which should be treated as such (for other types of spinal cord deformations, see Fig. 9). The most frequently malformation mentioned in the literature is lordosis [34-37]. However, the term "lordosis" has also frequently been used as a generic term for any type of curvature of the spine [38]. Another study, however, correctly identified lordosis, but annotated "scoliosis" as "spinal column flexure (tail defect)" and also listed "kyphosis" rather appears to be a break in the notochord, which we would suggest to call notochord fragmentation [39]. In some cases, "modified structure of chorda" [69], "body shape" [69], "notochord anomalies", "tail anomalies", and "kinks (wavy, curled, bend)" were employed to describe spinal cord malformations without further distinction [83]. No further publications could be found, directly discussing the different curvatures observed in zebrafish embryos, although-according to the present study-spinal curvature is a group of endpoints quite frequently observed (Table 2); with the literature providing the further examples [55, 84-90].

Further effects with limited regeneration potential include impaired fin development such as the tailfin fraying (Fig. 8d) and underdeveloped pectoral fins (Fig. 8e). Common summarising surrogate terms are "fin morphology", "tail morphology" [69], and "tail malformation" [91], which, however, do not allow a separation between changes of the spinal cord and the fin(s) itself. 
Figure 8 also illustrates the examples of reduced eye development (Figs. 8f, g) and lack of otolith formation (Fig. 8h). In literature, these endpoints are commonly referred to as "eye malformation" or "deficiencies of eyes and otic vesicles", providing no further information [83, 92]. Since the zebrafish eye contains fully differentiated cells connecting to the brain via the optic nerve by $28 \mathrm{hpf}$ [93], its development can be impacted very early on, thus being of environmental importance. Further craniofacial malformations (Figs. 8i, j) can be less easily recorded, since observation is usually obstructed by active swimming from $120 \mathrm{hpf}$. Craniofacial deformations include the shortening or lengthening of the (lower) jaw, as well as general disorganisation of skeletal elements. Recent studies discovered a connection between histone deacetylase (HDAC) inhibition and craniofacial malformation [9496] as well as neural tube defects [97-100]. These observations have already been implemented in the established AOPs (can be found under: https://aopwiki.org/aops/274 and https://aopwiki.org/aops/275), thus presenting an important link between effects in mammals and zebrafish embryos. Again, however, the recent publications used a diverse array of nomenclature: "jaw malformation" [92]; "facial structure morphology", "jaw and pharyngeal arch morphology" [69], and "lower jaw anomalies" describing pharyngeal arches' shape [83]). All of the examples listed above illustrate the need for more differentiated assessment of deviations from normal zebrafish development as well as a harmonisation of nomenclature.

\section{Additional sublethal morphological alterations in zebrafish embryos}

Figure 9 illustrates the examples of less frequently described sublethal endpoints such as morphologically discernible yolk alterations, which can be identified from 48 hpf (Fig. 9a). Reduced yolk resorption (Figs. 9b, c) only becomes particularly evident from $96 \mathrm{hpf}$, when healthy embryos begin to deplete its nutrient resources. The present study identified reduced yolk resorption among valproic acid-related endpoints, which have been interpreted as symptoms of the embryonic malabsorption syndrome [101]. Again, however, numerous studies only used summary terms such as "yolk", which might include yolk oedemata, yolk depletion, or yolk deformations, thus being less informative [69].

Reduced pigmentation can be seen at various degrees (Figs. 9d-f): either, the entire organism (Figs. 9d, e) or specific organs (Fig. 9f) may be affected. As an endpoint, pigmentation may be affected by a multitude of pathways, and there is only limited information about underlying mechanisms. As a final example of morphological effects, deformation or fragmentation of the notochord may occur at variable degrees of severity (Figs. 9g, h).
Notochord malformations may develop from an early stage (Fig. 9g) and are likely to persist (Fig. 9h), which, in severe cases, may lead to notochord fragmentation with multiple breaks in the notochord. Notochord malformation has been termed as "chorda malformation" or "larvae showing a bent spine" [91] or has simply been mentioned as "notochord morphology" without further differentiation [69]. It should be noted that notochord malformation is an entirely different pathology to, e.g., lordosis, and should be clearly differentiated. Overall, notochord malformation and fragmentation can be observed quite frequently (cf. Table 2).

\section{Alterations in zebrafish embryo behaviour}

Table 2 also includes behavioural changes such as tremor and modified spontaneous movement as additional "morphological" observations, which are, however, difficult to document without a special hardware and software. Such effects can often be linked to neurotoxic effects such as inhibition of acetylcholinesterase [102], which leads to minute erratic movements. Unfortunately, behavioural endpoints are frequently ignored in morphology-based teratogenicity experiments and have only rarely been discussed in this context. Occasionally, summarising terms such as "motility" and "locomotor activity" without further explanation (decrease or increase) can be found $[91,103,104])$. An example of a more informative term is "seizure liability" as "incidence of high-speed movements characteristic of seizure activity" [30]. Although the quantitative determination of behavioural effects requires video tracking and elaborate analysis [105-110], the presence or absence of behavioural changes can easily be recorded in a standard FET test and be used as a first indicator of, e.g., a neurotoxic potential of the test compound [111].

\section{Conclusions}

The present study on morphological effects by a wide array of test compounds with a wide spectrum of modesof-action illustrates that toxic exposure of zebrafish embryos may lead to multiple developmental alterations beyond those listed in OECD TG 236 for the FET. The implementation of additional endpoints beyond the four core endpoints prescribed by OECD TG 236 adds significant value to the FET as a validated test system. However, the study also documents that the overall number of morphological alterations is limited-as holds true for other morphological criteria such as, e.g., histopathological and ultrastructural observations. As a consequence, morphological observations may serve as an important source of indicators for potential toxic mechanisms; additional (molecular) studies may usually be required to elucidate underlying pathways. The comparability and benefit of 
FET studies could significantly be improved by a complete and more differentiated description of the observations and a harmonisation of the nomenclature used. Likewise, an at least approximate quantification of the observations (e.g., by morphological scoring) would certainly increase the reliability and robustness of the studies and, thus, the overall value of FET studies for regulatory (eco)toxicology. Given such improvements, FET data could make an important contribution to modern hazard and risk assessment compatible with the $3 \mathrm{R}$ principles.

\section{Supplementary information}

Supplementary information accompanies this paper at https://doi. org/10.1186/s12302-020-00398-3.

Additional file 1. Catalogue of adverse effects in the fish embryo acute toxicity (FET) test.

\begin{abstract}
Abbreviations
AFT: Acute fish toxicity test; AOP: Adverse outcome pathway; DMSO: Dimethyl sulfoxide; EC: Effect concentration; ECHA: European Chemical Agency; FET: Fish embryo acute toxicity test; GHS: Globally Harmonised System of Classification, Labelling and Packaging of Chemicals; HPF: Hours post-fertilisation; LC: Lethal concentration; MPP+: 1-Methyl-4-pyridinium iodide; OECD: Organization for economic co-operation and development; PBT: Persistence, bioaccumulation and toxicity assessment; PCB 180: Polychlorinated biphenyl 180; PE: Pericardial oedemata; PNEC: Predicted no-effect concentration; REACH: Registration, evaluation, authorization, and restriction of chemicals; STS: Sodium tetradecyl sulphate; TG: Test guideline; YE: Yolk oedemata.
\end{abstract}

\section{Acknowledgements}

Zinc pyrithione was tested by MSc Christoph Gade. Part of the range-finding experiments was carried out by Lisa Hanslik, Ann-Kathrin Lörracher, Annika Batel, Susanna Mieck, and Florian Zindler.

\section{Authors' contributions}

KB tested 2,2-dimethyl valeric acid, 2-ethylbutyric acid, 2-ethylhexanoic acid, 2-methylhexanoic acid, 2-methylpentanoic acid, 2-propylheptanoic acid, 4-ene-valproic acid, 4-pentenoic acid, hexanoic acid and valproic acid and was a contributor in writing the manuscript. RS tested 1-octanol, 2,3,6-trimethyl phenol, 3,4-dichloroaniline, 2,4-dinitrophenol, dinitro-o-cresol 6-Methyl-5heptene-2-one, carbamazepine, copper (II) sulphate pentahydrate, DMSO, ethanol, luviquat, malathion, merquat, methylmercury (II) chloride, prochloraz, sodium chloride, STS, triclosan and triethylene glycol. RH tested acrylamide, carbaryl, clofibrate, colchicine, hexachlorophene, ibuprofen, MPP +, paracetamol, paraquat, PCB 180, rifampicin, rotenone, sufisoxazole, taxol, tebuconazole, tolbutamide, and triphenylphosphate, and was a major contributor in writing the manuscript. LB was a contributor in writing the manuscript and aided in the data analysis. TB was a contributor in the writing of the manuscript. All authors read and approved the final manuscript.

\section{Funding}

Open Access funding enabled and organized by Projekt DEAL. This project has received funding from the European Union's Horizon 2020 research and innovation programme under Grand agreement No 681102.

\section{Availability of data and materials \\ The datasets used and/or analysed the current study are available from the corresponding author on reasonable request.}

\section{Ethics approval and consent to participate}

The work was conducted in strict accordance with governmental legislations in the aquatic toxicology research group of the University of Heidelberg (Licence number: 35-9185.64/BH).
Consent for publication

Not applicable.

\section{Competing interests}

The authors declare that they have no competing interests.

\begin{abstract}
Author details
${ }_{1}^{1}$ Aquatic Ecology and Toxicology, Centre for Organismal Studies, University of Heidelberg, Im Neuenheimer Feld 504, 69120 Heidelberg, Germany. 2 Present Address: SCC GmbH, Am Grenzgraben 11, 55545 Bad Kreuznach, Germany.
\end{abstract}

Received: 29 June 2020 Accepted: 14 September 2020

Published online: 29 September 2020

\section{References}

1. Lammer E, Carr GJ, Wendler K et al (2009) Is the fish embryo toxicity test (FET) with the zebrafish (Danio rerio) a potential alternative for the fish acute toxicity test? Comp Biochem Physiol C Toxicol Pharmacol 149:196-209. https://doi.org/10.1016/j.cbpc.2008.11.006

2. Scholz S, Ortmann J, Klüver N, Léonard M (2014) Extensive review of fish embryo acute toxicities for the prediction of GHS acute systemic toxicity categories. Regul Toxicol Pharmacol 69:572-579. https://doi. org/10.1016/j.yrtph.2014.06.004

3. ECHA (2017) Chapter 11: Pbt/vpvb assessment. In: Guidance and information requirements and chemical safety assessment. pp 1-158

4. OECD (2016) Test No. 489: In Vivo Mammalian Alkaline Comet Assay. OECD

5. Paparella M, Scholz S, Belanger S, et al (2020) Limitations and uncertainties of acute fish toxicity assessment are reducible by alternatives. ALTEX Altern zu Tierexperimenten In Press

6. European Commission (2000) Directiev 2000/60/EC of the European Parliament and of the Council of 23 October 2000 establishing a framework for the community action in the field of water policy

7. Norberg-King TJ, Embry MR, Belanger SE et al (2018) An international perspective on the tools and concepts for effluent toxicity assessments in the context of animal alternatives: reduction in vertebrate use. Environ Toxicol Chem 37:2745-2757. https://doi.org/10.1002/etc.4259

8. Halder M, Léonard M, Iguchi T et al (2010) Regulatory aspects on the use of fish embryos in environmental toxicology. Integr Environ Assess Manag 6:484-491. https://doi.org/10.1002/ieam.48

9. Embry MR, Belanger SE, Braunbeck TA et al (2010) The fish embryo toxicity test as an animal alternative method in hazard and risk assessment and scientific research. Aquat Toxicol 97:79-87. https://doi. org/10.1016/j.aquatox.2009.12.008

10. Kohlpoth M, Rusche B (1992) Die Verwendung von Fischzellkulturen als Ersatz für den Fischtest im Abwasserabgabengesetz. In: Schöffl H, Schulte-Hermann R, Tritthart H (eds) Möglichkeiten und Grenzen der Reduktion von Tierversuchen, Ersatz- und Ergänzungsmethoden zu Tierversuchen. Springer, Vienna, pp 118-121

11. BraunbeckT (2020) Development of an OECD guidance document for the application of OECD test guideline 236 (acute fish embryo toxicity test): The chorion structure and biotransformation capacities of zebrafish as boundary conditions for OECD test guideline 236-German cont. UBA Texte In Press

12. Hrovat M, Segner $H$, Jeram S (2009) Variability of in vivo fish acute toxicity data. Regul Toxicol Pharmacol 54:294-300. https://doi.org/10.1016/j. yrtph.2009.05.013

13. Braunbeck T, Kais B, Lammer E et al (2015) The fish embryo test (FET): origin, applications, and future. Environ Sci Pollut Res Int 22:1624716261. https://doi.org/10.1007/s11356-014-3814-7

14. European Union (2007) Regulation (EC) No 1907/2006 of the European Parliament and of the council of 18 December 2006 concerning the Registration, Evaluation, Authorisation and Restriction of Chemicals (REACH), establishing a European Chemicals Agency, amending Directive 1999/4

15. European Commission (2009) Regulation (EC) no 1223/2009 of the European parliament and of the council of 30 November 2009 on cosmetic products 
16. Russell WMS, Burch RL (1959) The principles of humane experimental techniques. Methuen, London

17. Villeneuve DL, Crump D, Garcia-Reyero N et al (2014) Adverse outcome pathway (AOP) development i: strategies and principles. Toxicol Sci 142:312-320. https://doi.org/10.1093/toxsci/kfu199

18. Villeneuve D, Volz DC, Embry MR et al (2014) Investigating alternatives to the fish early-life stage test: a strategy for discovering and annotating adverse outcome pathways for early fish development. Environ Toxicol Chem 33:158-169. https://doi.org/10.1002/etc.2403

19. Castaño A, Bols N, Braunbeck T et al (2003) The use of fish cells in ecotoxicology. The report and recommendations of ECVAM Workshop 47. Altern Lab Anim 31:317-351. https://doi.org/10.1177/0261192903 03100314

20. Braunbeck T, Boettcher $\mathrm{M}$, Hollert $\mathrm{H}$ et al (2005) Towards an alternative for the acute fish $L C(50)$ test in chemical assessment: the fish embryo toxicity test goes multi-species_an update. Altex 22:87-102. https:// doi.org/10.1007/s10811-007-9297-x

21. Sipes NS, Martin MT, Reif DM et al (2011) Predictive models of prenatal developmental toxicity from ToxCast high-throughput screening data. Toxicol Sci 123:1-54. https://doi.org/10.1093/toxsci/kfr220

22. Embry MR, Bachman AN, Bell DR et al (2014) Risk assessment in the 21st century: roadmap and matrix. Crit Rev Toxicol 44:6-16. https://doi. org/10.3109/10408444.2014.931924

23. Lillicrap A, Belanger S, Burden N et al (2016) Alternative approaches to vertebrate ecotoxicity tests in the 21st century: a review of developments over the last 2 decades and current status. Environ Toxicol Chem 35:2637-2646. https://doi.org/10.1002/etc.3603

24. Rovida C (2015) Toxicity testing in the 21 st century beyond environmental chemicals. Altex 32:171-181. https://doi.org/10.14573/altex .1506201

25. ISO (2007) International Standard Water Quality—determination of the acute toxicity of waste water to zebrafish eggs (Danio rerio)

26. Jacobs H, Dennefeld C, Féret B et al (2011) Retinoic acid drives aryl hydrocarbon receptor expression and is instrumental to dioxininduced toxicity during palate development. Environ Health Perspect 119:1590-1595. https://doi.org/10.1289/ehp.1003075

27. BraunbeckT, Lammer E (2006) Detailed review paper "Fish embryo toxicity assays". Ger Fed Environ, Agency, p 298

28. OECD (1981) OECD Guidelines for the Testing of Chemicals. OECD

29. Sobanska M, Scholz S, Nyman AM et al (2018) Applicability of the fish embryo acute toxicity (FET) test (OECD 236) in the regulatory context of registration, evaluation, authorisation, and restriction of chemicals (REACH). Environ Toxicol Chem 37:657-670. https://doi.org/10.1002/ etc. 4055

30. Eimon PM, Rubinstein AL (2009) The use of in vivo zebrafish assays in drug toxicity screening. Expert Opin Drug Metab Toxicol 5:393-401. https://doi.org/10.1517/17425250902882128

31. Hill AJ, Jones M, Dodd A, Diekmann H (2011) A review of developmental toxicity screening using zebrafish larvae. Toxicol Lett 205:115. https ://doi.org/10.1016/j.toxlet.2011.05.413

32. Hagstrom D, Truong L, Zhang S et al (2019) Comparative analysis of zebrafish and planarian model systems for developmental neurotoxicity screens using an 87-compound library. Toxicol Sci 167:45-57. https ://doi.org/10.1093/toxsci/kfy180

33. Belanger SE, Rawlings JM, Carr GJ (2013) Use of fish embryo toxicity tests for the prediction of acute fish toxicity to chemicals. Environ Toxicol Chem 32:1768-1783. https://doi.org/10.1002/etc.2244

34. Matson CW, Timme-Laragy AP, Di Giulio RT (2008) Fluoranthene, but not benzo[a]pyrene, interacts with hypoxia resulting in pericardial effusion and lordosis in developing zebrafish. Chemosphere 74:129-154. https ://doi.org/10.1038/jid.2014.371

35. Xu Z, Williams FE, Liu M-C (2011) Developmental toxicity of dextrmethorphan in zebrafish embryos/larvae. J Appl Toxicol 31:157-163. https://doi.org/10.1038/jid.2014.371

36. Labonty M, Pray N, Yelick PC (2017) A zebrafish model of human fibrodysplasia ossificans progressiva. Zebrafish 14:293-304. https://doi. org/10.1089/zeb.2016.1398

37. Seok SH, Park JH, Baek MW et al (2006) Specific activation of the human HSP70 promoter by copper sulfate in mosaic transgenic zebrafish. J Biotechnol 126:406-413. https://doi.org/10.1016/j.jbiotec.2006.04.029
38. Issa O, Hassoun EA, Williams FE (2019) Developmental effects of trichloroacetate in Zebrafish embryos: association with the production of superoxide anion. J Biochem Mol Toxicol 33:1-6. https://doi. org/10.1002/jbt.22259

39. Şişman T, Geyikoğlu F (2008) The teratogenic effects of polychlorinated naphthalenes (PCNs) on early development of the zebrafish (Danio rerio). Environ Toxicol Pharmacol 25:83-88. https://doi.org/10.1016/j. etap.2007.09.001

40. OECD (2012) Validation Report (Phase 2) for the Zebrafish Embryo Toxicity Test (No. 179)

41. OECD (2011) Validation report (Phase I) for the zebrafish embryo toxicity test part I OECD TG 157

42. OECD (2014) Validation Report (Phase I) for the zebrafish embryo toxicity testing part 2 (No. 157)

43. OECD (2013) Test No. 236: Fish Embryo Acute Toxicity (FET) Test. OECD

44. Nagel R (2002) DarT: the embryo test with the Zebrafish Danio rerio-a general model in ecotoxicology and toxicology. Altex 19:38-48

45. Strähle U, Scholz S, Geisler R et al (2012) Zebrafish embryos as an alternative to animal experiments-A commentary on the definition of the onset of protected life stages in animal welfare regulations. Reprod Toxicol 33:128-132. https://doi.org/10.1016/j.reprotox.2011.06.121

46. European Union (2010) Directive 2010/63/EU of the European parliament and of the council of 22 September 2010 on the protection of animals used for scientific purposes

47. Horie Y, Yamagishi T, Takahashi H et al (2017) Assessment of the lethal and sublethal effects of 20 environmental chemicals in zebrafish embryos and larvae by using OECD TG 212. J Appl Toxicol 37:12451253. https://doi.org/10.1002/jat.3487

48. Jeffries MKS, Stultz AE, Smith AW et al (2015) The fish embryo toxicity test as a replacement for the larval growth and survival test: a comparison of test sensitivity and identification of alternative endpoints in zebrafish and fathead minnows. Environ Toxicol Chem 34:1369-1381. https://doi.org/10.1002/etc.2932

49. Incardona JP, Scholz NL (2016) The influence of heart developmental anatomy on cardiotoxicity-based adverse outcome pathways in fish. Aquat Toxicol 177:515-525. https://doi.org/10.1016/j.aquat ox.2016.06.016

50. Cherr GN, Fairbairn E, Whitehead A (2017) Impacts of petroleumderived pollutants on fish development. Annu Rev Anim Biosci 5:185-203. https://doi.org/10.1146/annurev-animal-022516-022928

51. Shaw BJ, Liddle CC, Windeatt KM, Handy RD (2016) A critical evaluation of the fish early-life stage toxicity test for engineered nanomaterials: experimental modifications and recommendations. Arch Toxicol 90:2077-2107. https://doi.org/10.1007/s00204-016-1734-7

52. Bereketoglu C, Pradhan A (2019) Comparative transcriptional analysis of methylparaben and propylparaben in zebrafish. Sci Total Environ 671:129-139. https://doi.org/10.1016/j.scitotenv.2019.03.358

53. Moreman J, Lee O, Trznadel M et al (2017) Acute toxicity, teratogenic, and estrogenic effects of Bisphenol A and Its Alternative Replacements Bisphenol S, Bisphenol F, and Bisphenol AF in zebrafish embryo-larvae. Environ Sci Technol 51:12796-12805. https://doi.org/10.1021/acs. est.7b03283

54. Parsons A, Lange A, Hutchinson TH et al (2019) Molecular mechanisms and tissue targets of brominated flame retardants, BDE-47 and TBBPA, in embryo-larval life stages of zebrafish (Danio rerio). Aquat Toxicol 209:99-112. https://doi.org/10.1016/j.aquatox.2019.01.022

55. Zezza D, Tait S, Della Salda L et al (2019) Toxicological, gene expression and histopathological evaluations of environmentally realistic concentrations of polybrominated diphenyl ethers PBDE- 47, PBDE-99 and PBDE-209 on zebrafish embryos. Ecotoxicol Environ Saf. https://doi. org/10.1016/j.ecoenv.2019.109566

56. Awoyemi OM, Kumar N, Schmitt C et al (2019) Behavioral, molecular and physiological responses of embryo-larval zebrafish exposed to types I and II pyrethroids. Chemosphere 219:526-537. https://doi. org/10.1016/j.chemosphere.2018.12.026

57. Pype C, Verbueken E, Saad MA et al (2015) Incubation at $32.5^{\circ} \mathrm{C}$ and above causes malformations in the zebrafish embryo. Reprod Toxicol 56:56-63. https://doi.org/10.1016/j.reprotox.2015.05.006

58. Gibert Y, Sassi-Messai S, Fini J-B et al (2011) Bisphenol A induces otolith malformations during vertebrate embryogenesis. BMC Dev Biol. https ://doi.org/10.1186/1471-213X-11-4 
59. van den Brandhof E-J, Montforts M (2010) Fish embryo toxicity of carbamazepine, diclofenac and metoprolol. Ecotoxicol Environ Saf 73:1862-1866. https://doi.org/10.1016/j.ecoenv.2010.08.031

60. Reimers MJ, Flockton AR, Tanguay RL (2004) Ethanol- and acetaldehydemediated developmental toxicity in zebrafish. Neurotoxicol Teratol 26:769-781. https://doi.org/10.1016/j.ntt.2004.06.012

61. Henn K, BraunbeckT (2011) Dechorionation as a tool to improve the fish embryo toxicity test (FET) with the zebrafish (Danio rerio). Comp Biochem Physiol C Toxicol Pharmacol 153:91-98. https://doi. org/10.1016/j.cbpc.2010.09.003

62. Strecker R, Weigt S, Braunbeck T (2013) Cartilage and bone malformations in the head of zebrafish (Danio rerio) embryos following exposure to disulfiram and acetic acid hydrazide. Toxicol Appl Pharmacol 268:221-231. https://doi.org/10.1016/j.taap.2013.01.023

63. Belanger SE, Balon EK, Rawlings JM (2010) Saltatory ontogeny of fishes and sensitive early life stages for ecotoxicology tests. Aquat Toxicol 97:88-95. https://doi.org/10.1016/j.aquatox.2009.11.020

64. Venzin OF, Oates AC (2020) What are you synching about? Emerging complexity of Notch signaling in the segmentation clock. Dev Biol 460:40-54. https://doi.org/10.1016/j.ydbio.2019.06.024

65. Hallare AV, Köhler H-R, Triebskorn R (2004) Developmental toxicity and stress protein responses in zebrafish embryos after exposure to diclofenac and its solvent, DMSO. Chemosphere 56:659-666. https:// doi.org/10.1016/j.chemosphere.2004.04.007

66. Li VWT, Tsui MPM, Chen X et al (2016) Effects of 4-methylbenzylidene camphor (4-MBC) on neuronal and muscular development in zebrafish (Danio rerio) embryos. Environ Sci Pollut Res 23:8275-8285. https://doi. org/10.1007/s11356-016-6180-9

67. Mendis JC, Tennakoon TK, Jayasinghe CD (2018) Zebrafish embryo toxicity of a binary mixture of pyrethroid insecticides: $d$-tetramethrin and cyphenothrin. J Toxicol 2018:1-8. https://doi.org/10.1155/2018/41826 94

68. Oliveira R, Domingues I, Koppe Grisolia C, Soares AMVM (2009) Effects of triclosan on zebrafish early-life stages and adults. Environ Sci Pollut Res 16:679-688. https://doi.org/10.1007/s11356-009-0119-3

69. Brannen KC, Panzica-Kelly JM, Danberry TL, Augustine-Rauch KA (2010) Development of a zebrafish embryo teratogenicity assay and quantitative prediction model. Birth Defects Res Part B Dev Reprod Toxicol 89:66-77. https://doi.org/10.1002/bdrb.20223

70. Huang M, Jiao J, Wang J et al (2018) Characterization of acrylamideinduced oxidative stress and cardiovascular toxicity in zebrafish embryos. J Hazard Mater 347:451-460. https://doi.org/10.1016/j.jhazm at.2018.01.016

71. Berndt C, Poschmann G, Sthler K et al (2014) Zebrafish heart development is regulated via glutaredoxin 2 dependent migration and survival of neural crest cells. Redox Biol 2:673-678. https://doi.org/10.1016/j. redox.2014.04.012

72. Li YX, Zdanowicz M, Young L et al (2003) Cardiac neural crest in zebrafish embryos contributes to myocardial cell lineage and early heart function. Dev Dyn 226:540-550. https://doi.org/10.1002/ dvdy.10264

73. Ni J, Wang H, Wei $X$ et al (2020) Isoniazid causes heart looping disorder in zebrafish embryos by the induction of oxidative stress. BMC Pharmacol Toxicol. https://doi.org/10.1186/s40360-020-0399-2

74. Roy NM, Ochs J, Zambrzycka E, Anderson A (2016) Glyphosate induces cardiovascular toxicity in Danio rerio. Environ Toxicol Pharmacol 46:292-300. https://doi.org/10.1016/j.etap.2016.08.010

75. Antkiewicz DS, Peterson RE, Heideman W (2006) Blocking expression of AHR2 and ARNT1 in zebrafish larvae protects against cardiac toxicity of 2,3,7,8-tetrachlorodibenzo-p-dioxin. Toxicol Sci 94:175-182. https://doi. org/10.1093/toxsci/kfl093

76. Sarmah S, Marrs JA (2013) Complex cardiac defects after ethanol exposure during discrete cardiogenic events in zebrafish: prevention with folic acid. Dev Dyn 242:1184-1201. https://doi.org/10.1002/dvdy.24015

77. Wu S, Fisher J, Naciff J et al (2013) Framework for identifying chemicals with structural features associated with the potential to act as developmental or reproductive toxicants. Chem Res Toxicol 26:1840-1861. https://doi.org/10.1021/tx400226u

78. Haggard DE, Das SR, Tanguay RL (2017) Comparative toxicogenomic responses to the flame retardant mITP in developing zebrafish. Chem
Res Toxicol 30:508-515. https://doi.org/10.1021/acs.chemrestox.6b004 23

79. Manjunatha B, Han L, Kundapur RR et al (2020) Herbul black henna (hair dye) causes cardiovascular defects in zebrafish (Danio rerio) embryo model. Environ Sci Pollut Res 27:14150-14159. https://doi.org/10.1007/ s11356-020-07762-z

80. Lee JS, Morita Y, Kawai YK et al (2020) Developmental circulatory failure caused by metabolites of organophosphorus flame retardants in zebrafish, Danio rerio. Chemosphere. https://doi.org/10.1016/j.chemo sphere.2019.125738

81. Pennanen SM, Heiskanen KM, Savolainen KM, Komulainen H (2000) Effects of 2-ethylhexanoic acid on the production of reactive oxygen species in human polymorphonuclear leukocytes in vitro. Toxicol Lett 117:79-84. https://doi.org/10.1016/s0378-4274(00)00243-5

82. Meneghetti G, Skobo T, Chrisam M et al (2020) Zebrafish ambra1a and ambra1b silencing affect heart development. Zebrafish 17:163-176. https://doi.org/10.1089/zeb.2020.1860

83. Yamashita A, Inada $H$, Chihara K et al (2014) Improvement of the evaluation method for teratogenicity using zebrafish embryos. J Toxicol Sci 39:453-464. https://doi.org/10.2131/jts.39.453

84. Li R, Wang H, Mi C et al (2019) The adverse effect of TCIPP and TCEP on neurodevelopment of zebrafish embryos/larvae. Chemosphere 220:811-817. https://doi.org/10.1016/j.chemosphere.2018.12.198

85. Liu $X$, Jung D, Jo A et al (2016) Long-term exposure to triphenylphosphate alters hormone balance and HPG, HPI, and HPT gene expression in zebrafish (Danio rerio). Environ Toxicol Chem 35:2288-2296. https:// doi.org/10.1002/etc.3395

86. Rangasamy B, Hemalatha D, Shobana C et al (2018) Developmental toxicity and biological responses of zebrafish (Danio rerio) exposed to anti-inflammatory drug ketoprofen. Chemosphere 213:423-433. https ://doi.org/10.1016/j.chemosphere.2018.09.013

87. Sun G, Liu K (2017) Developmental toxicity and cardiac effects of butyl benzyl phthalate in zebrafish embryos. Aquat Toxicol 192:165-170. https://doi.org/10.1016/j.aquatox.2017.09.020

88. Yan Z, Huang X, Xie Y et al (2019) Macrolides induce severe cardiotoxicity and developmental toxicity in zebrafish embryos. Sci Total Environ 649:1414-1421. https://doi.org/10.1016/j.scitotenv.2018.07.432

89. Yang X, Sun Z, Wang W et al (2018) Developmental toxicity of synthetic phenolic antioxidants to the early life stage of zebrafish. Sci Total Environ 643:559-568. https://doi.org/10.1016/j.scitotenv.2018.06.213

90. Zou Y, Zhang Y, Han L et al (2017) Oxidative stress-mediated developmental toxicity induced by isoniazide in zebrafish embryos and larvae. $J$ Appl Toxicol 37:842-852. https://doi.org/10.1002/jat.3432

91. Beker van Woudenberg A, Snel C, Rijkmans E et al (2014) Zebrafish embryotoxicity test for developmental (neuro)toxicity: demo case of an integrated screening approach system using anti-epileptic drugs. Reprod Toxicol 49:101-116. https://doi.org/10.1016/j.repro tox.2014.07.082

92. Teixidó E, Kießling TR, Krupp E et al (2019) Automated morphological feature assessment for zebrafish embryo developmental toxicity screens. Toxicol Sci 167:438-449. https://doi.org/10.1093/toxsci/kfy250

93. Morris AC, Fadool JM (2005) Studying rod photoreceptor development in zebrafish. Physiol Behav 86:306-313. https://doi.org/10.1016/j.physb eh.2005.08.020

94. Pillai R, Coverdale LE, Dubey G, Martin CC (2004) Histone deacetylase 1 (HDAC-1) required for the normal formation of craniofacial cartilage and pectoral fins of the zebrafish. Dev Dyn 231:647-654. https://doi. org/10.1002/dvdy.20168

95. Kong Y, Grimaldi M, Curtin E et al (2014) Neural crest development and craniofacial morphogenesis is coordinated by nitric oxide and histone acetylation. Chem Biol 21:488-501. https://doi.org/10.1016/j.chemb iol.2014.02.013

96. Rao A, LaBonne C (2018) Histone deacetylase activity has an essential role in establishing and maintaining the vertebrate neural crest. Development. https://doi.org/10.1242/dev.163386

97. Gurvich N, Berman MG, Wittner BS et al (2005) Association of valproateinduced teratogenesis with histone deacetylase inhibition in vivo. FASEB J 19:1166-1168. https://doi.org/10.1096/fj.04-3425fje

98. Massa V, Cabrera RM, Menegola E et al (2005) Valproic acid-induced skeletal malformations: associated gene expression cascades. 
Pharmacogenet Genomics 15:787-800. https://doi.org/10.1097/01. fpc.0000170914.11898.3a

99. Murko C, Lagger S, Steiner M et al (2013) Histone deacetylase inhibitor Trichostatin A induces neural tube defects and promotes neural crest specification in the chicken neural tube. Differentiation 85:55-66. https ://doi.org/10.1016/j.diff.2012.12.001

100. Menegola E, Di Renzo F, Broccia ML et al (2005) Inhibition of histone deacetylase activity on specific embryonic tissues as a new mechanism for teratogenicity. Birth Defects Res Part B Dev Reprod Toxicol 74:392-398. https://doi.org/10.1002/bdrb.20053

101. Raldúa D, André M, Babin PJ (2008) Clofibrate and gemfibrozil induce an embryonic malabsorption syndrome in zebrafish. Toxicol Appl Pharmacol 228:301-314. https://doi.org/10.1016/j.taap.2007.11.016

102. Schock EN, Ford WC, Midgley KJ et al (2012) The effects of carbaryl on the development of zebrafish (Danio rerio) embryos. Zebrafish 9:169-178. https://doi.org/10.1089/zeb.2012.0747

103. Kanungo J, Cuevas E, Ali S, Paule M (2014) Zebrafish model in drug safety assessment. Curr Pharm Des 20:5416-5429. https://doi. org/10.2174/1381612820666140205145658

104. Weichert FG, Floeter C, Meza Artmann AS, Kammann U (2017) Assessing the ecotoxicity of potentially neurotoxic substances-evaluation of a behavioural parameter in the embryogenesis of Danio rerio. Chemosphere 186:43-50. https://doi.org/10.1016/j.chemosphere.2017.07.136

105. De Esch C, Slieker R, Wolterbeek A et al (2012) Zebrafish as potential model for developmental neurotoxicity testing. A mini review. Neurotoxicol Teratol 34:545-553. https://doi.org/10.1016/j.ntt.2012.08.006

106. Horzmann K, Freeman J (2016) Zebrafish get connected: investigating neurotransmission targets and alterations in chemical toxicity. Toxics. https://doi.org/10.3390/toxics4030019
107. Legradi J, el Abdellaoui N, van Pomeren M, Legler J (2015) Comparability of behavioural assays using zebrafish larvae to assess neurotoxicity. Environ Sci Pollut Res Int 22:16277-16289. https://doi.org/10.1007/ s11356-014-3805-8

108. Miller GW, Chandrasekaran V, Yaghoobi B, Lein PJ (2018) Opportunities and challenges for using the zebrafish to study neuronal connectivity as an endpoint of developmental neurotoxicity. Neurotoxicology 67:102-111. https://doi.org/10.1016/j.neuro.2018.04.016

109. Faimali M, Gambardella C, Costa E et al (2017) Old model organisms and new behavioral end-points: swimming alteration as an ecotoxicological response. Mar Environ Res 128:36-45. https://doi.org/10.1016/j. marenvres.2016.05.006

110. Tierney KB (2011) Behavioural assessments of neurotoxic effects and neurodegeneration in zebrafish. Biochim Biophys Acta Mol Basis Dis 1812:381-389. https://doi.org/10.1016/j.bbadis.2010.10.011

111. Zindler F, Beedgen F, Brandt D et al (2019) Analysis of tail coiling activity of zebrafish (Danio rerio) embryos allows for the differentiation of neurotoxicants with different modes of action. Ecotoxicol Environ Saf. https://doi.org/10.1016/j.ecoenv.2019.109754

\section{Publisher's Note}

Springer Nature remains neutral with regard to jurisdictional claims in published maps and institutional affiliations.

\section{Submit your manuscript to a SpringerOpen ${ }^{\odot}$ journal and benefit from:}

- Convenient online submission

- Rigorous peer review

- Open access: articles freely available online

- High visibility within the field

- Retaining the copyright to your article

Submit your next manuscript at $\boldsymbol{\nabla}$ springeropen.com 